\title{
Egg consumption and cardiovascular risk: a dose-response meta-analysis of prospective cohort studies
}

\author{
Justyna Godos ${ }^{1}$. Agnieszka Micek ${ }^{2}$. Tomasz Brzostek ${ }^{3}$ - Estefania Toledo ${ }^{4,5,6}$ - Licia lacoviello ${ }^{7,8}$ - Arne Astrup ${ }^{9}$. \\ Oscar H. Franco ${ }^{10,11}$. Fabio Galvano $^{12} \cdot$ Miguel A. Martinez-Gonzalez $^{4,5,6,13} \cdot$ Giuseppe Grosso $^{12}$ (1)
}

Received: 21 January 2020 / Accepted: 21 July 2020 / Published online: 31 August 2020

(c) The Author(s) 2020

\begin{abstract}
Purpose Cardiovascular disease (CVD) is a leading cause of mortality globally and is strongly influenced by dietary risk factors. The aim was to assess the association between egg consumption and risk of CVD risk/mortality, including coronary heart disease (CHD), stroke, and heart failure.

Methods MEDLINE, Embase, and Web of Science databases were searched through April 2020 for prospective studies. Two independent reviewers screened and extracted the data through standardized methods. Size effects were calculated as summary relative risks (SRRs) in a dose-response fashion through random-effects meta-analyses.

Results Thirty-nine studies including nearly 2 million individuals and 85,053 CHD, 25,103 stroke, 7536 heart failure, and 147,124 CVD cases were included. The summary analysis including 17 datasets from 14 studies conducted on CVD (incidence and/or mortality) showed that intake of up to six eggs per week is inversely associated with CVD events, when compared to no consumption [for four eggs per week, SRR $=0.95$ (95\% CI: 0.90; 1.00)]; a decreased risk of CVD incidence was observed for consumption of up to one egg per day [SRR =0.94 (95\% CI: 0.89; 0.99)]. The summary analysis for CHD incidence/mortality including 24 datasets from 16 studies showed a decreased risk up to two eggs per week [(SRR $=0.96$ $(95 \%$ CI: $0.91 ; 1.00)]$. No associations were retrieved with risk of stroke. The summary analysis for heart failure risk including six datasets from four studies showed that intake of one egg per day was associated with increased risk raising for higher intakes compared to no consumption [for 1 egg per day, $\mathrm{SRR}=1.15$ (95\% CI:1.02; 1.30)]. After considering GRADE criteria for strength of the evidence, it was rated low for all outcomes but stroke, for which it was moderate (yet referring to no risk). Conclusion There is no conclusive evidence on the role of egg in CVD risk, despite the fact that higher quality studies are warranted to obtain stronger evidence for a possible protection of CVD associated with moderate weekly egg consumption compared to no intake; equally, future studies may strengthen the evidence for increased heart failure risk associated with high regular egg consumption.
\end{abstract}

Keywords Egg $\cdot$ Cardiovascular disease $\cdot$ Stroke $\cdot$ Prospective cohort $\cdot$ Meta-analysis $\cdot$ Dose-response

Miguel A. Martinez-Gonzalez and Giuseppe Grosso have contributed equally.

Electronic supplementary material The online version of this article (https://doi.org/10.1007/s00394-020-02345-7) contains supplementary material, which is available to authorized users.

Giuseppe Grosso

giuseppe.grosso@unict.it

Extended author information available on the last page of the article

\section{Introduction}

Cardiovascular disease (CVD) represents the leading cause of mortality globally, responsible for a total of about 18 million deaths in 2017, while increasing from 12.3 million in 1990 [1]. Nutritional risk factors have been considered of paramount importance to prevent the global burden of CVD [2,3]. Among the many factors widely studied over the last decades, dietary cholesterol has been the focus of major attention due to the relationship between blood cholesterol and increased risk of CVD firstly observed in the Framingham Heart Study nearly half century ago and ever since considered as risk factor [4]. Eggs, as major sources 
of dietary cholesterol (200-300 mg/100 g, about $180 \mathrm{mg}$ per medium egg), have been subsequently advised to be consumed in moderation to lower dietary cholesterol intake [5]. However, current evidence on the association between dietary cholesterol and CVD risk is not consistent [6]. In 2000 the American Heart Association advised consumption of up to one egg per day [7] and nearly 10 years later the US Dietary Guidelines Advisory Committee eliminated cholesterol restrictions from the latest US dietary guidelines [8]. Nonetheless, the general opinion on egg consumption might be misled and food advertising and media campaigns sponsoring and claiming cholesterol-free products as healthier (sometimes supplemented with added sugars) are common. As specifically for egg consumption, a comprehensive summary of evidence reported repeatedly null and contrasting findings, suggesting that meta-analytic studies need to better investigate potential confounding effects of relevant variables (i.e., sex, geographical area, adjustment for health or dietary variables, etc.) [9]. However, more prospective cohort studies have been published so far: specifically, a later study involving 6 US cohorts showed that egg consumption was associated with increased risk of CVD and that the detrimental cardiovascular effect of egg consumption was mainly driven by dietary cholesterol, once more suggesting the need to limit eggs consumption. In light of such considerations, the aim of this study was to update current evidence on the association between egg consumption and CVD risk while assessing whether confounding factors may play a role in such relation.

\section{Methods}

\section{Study design}

The design, analysis, and reporting of this study followed the meta-analysis of Observational Studies in Epidemiology (MOOSE) guidelines (ESM Table 1). A systematic search on PubMed (https://www.ncbi.nlm.nih.gov/pubme d/), EMBASE (https://www.embase.com/), Web of Science (www.webofknowledge.com) databases of studies published up to April 2020 was performed with the following search strategy: "[(egg OR eggs) AND (coronary heart disease OR myocardial infarction OR ischemic heart disease OR ischemic heart disease OR coronary artery disease OR heart disease OR stroke OR cardiovascular disease OR heart failure)] AND (cohort OR prospective OR longitudinal OR follow-up)". Studies were selected if they met the following inclusion criteria: (i) they were conducted on general population of human adults (i.e., no patients recruited in hospitals); (ii) had a prospective design; (iii) evaluated associations between egg intake and risk of CVD (fatal and nonfatal), cardiovascular-related outcomes (such as coronary heart disease [CHD] and stroke, fatal and non-fatal), and heart failure; (iv) assessed and reported hazard ratios (HRs) or risk ratios (RRs) and their corresponding 95\% CI for $\geq 3$ exposure categories (egg consumption) or provided HRs for increased intake of egg (as a continuous variable); and (v) provided a defined amount of egg consumption per category of exposure (i.e., servings of eggs per day or week). Reference lists of studies of interest were also examined for any additional study not previously identified. If more than one study was conducted on the same cohort, only the dataset including the larger number of individuals, the longest follow-up, or the most comprehensive data (i.e., number of cases and person-year for each category of exposure) was included on a case by case situation, depending on the analysis performed (see below). We did not exclude studies based on language or publication date. All references were evaluated by two independent reviewers (J.G., G.G.) with a third reviewer (A.M.) available in case of disagreement.

\section{Data extraction}

Data were abstracted by the two independent reviewers from each identified study using a standardized extraction form. The following information was collected: (i) first author name; (ii) year of publication; (iii) study cohort name and country; (iv) number, sex, and age (mean or range) of participants; (v) follow-up period; (vi) endpoints and cases; (vii) distributions of cases and person-years, HRs and 95\% CIs for all categories of exposure; (viii) covariates used in adjustments.

\section{Risk of bias and quality assessment}

Risk of bias was assessed using the Cochrane Risk of bias in Non-randomized Studies of Interventions (ROBINS-I) tool previously used in comprehensive meta-analyses with similar outcomes $[10,11]$. The tool consists of the following seven domains: (1) confounding, (2) selection of participants, (3) measurement of the exposure, (4) misclassification of exposure during follow-up, (5) missing data, (6) measurement of outcomes and (7) selective reporting. Two researchers (J.G. and A. M.) assessed the risk of bias independently. Any disagreements were resolved by consensus or by consultation of a third researcher.

\section{Outcomes}

Outcomes evaluated in the analyses included total CVD, $\mathrm{CHD}$, and stroke (including sub-types hemorrhagic and ischemic stroke) incidence and mortality. Also risk of heart failure incidence was assessed. 


\section{Statistical analysis}

When egg consumption was reported by ranges of intake, the midpoint of the range was used. When the highest category was open-ended, we assumed the width of the category to be the same as the adjacent category. When the lowest category was open-ended, we set the lower boundary to zero. Two-stage random-effects dose-response meta-analysis was performed to examine linear and non-linear relationship between egg consumption and CVD outcomes. In the first stage the method reported by Greenland and Orsini (generalized least-squares, GLS) was used to calculate study-specific coefficients on the basis of results across categories of egg consumption taking into account the correlation within each set of retrieved HRs $[12,13]$. Non-linear dose-response analysis was modeled using restricted cubic splines with three knots at fixed percentiles $(25 \%, 50 \%$, and $75 \%)$ of the distribution [14]. We combined the coefficients that had been estimated within each study by performing random-effects meta-analysis. In linear dose-response meta-analysis the method of DerSimonian and Laird was used and in non-linear dose-response meta-analysis the multivariate extension of the method of moments was used to estimate summary relative risks (SRRs). We calculated an overall $P$ value by testing that the two regression coefficients were simultaneously equal to zero. We then calculated a $P$ value for non-linearity by testing that the coefficient of the second spline was equal to zero. A subgroup analysis was conducted for those studies providing risk measures by diabetic status. A number of sensitivity analyses were conducted to test stability of results, including (i) exclusion of one study at the time, (ii) exclusion of studies that did not report number of cases and person-years for each category of exposure, and (iii) stratifying studies by variables of interest (such as sex, geographical localization of the cohort, level of adjustment for body mass index [BMI], diabetic status, and other dietary factors, and study quality). To facilitate interpretation of the results and easy application for dietary advices for the general population, the analyses were provided in depth for arbitrarily defined doses, such as "habitual" (daily) egg consumption corresponding to one egg per day, and "moderate" (weekly) egg consumption corresponding to four eggs per week. Publication bias was assessed with Egger's regression test. Statistical heterogeneity between studies was assessed using the $\chi^{2}$ test (defined as a $P$ value less than 0.10 ) and quantified through the multivariate generalization of the $I^{2}$ statistic. All analyses were performed with $\mathrm{R}$ software version 3.0.3, dosresmeta and mvmeta packages (Development Core Team, Vienna, Austria).

\section{Grading of the evidence}

The certainty of the evidence was assessed using the Grading of Recommendations, Assessment, Development, and Evaluation (GRADE) system [15]. Included observational studies started at low-certainty of evidence by default and then were downgraded or upgraded based on pre-specified criteria. Criteria to downgrade certainty included study limitations (weight of studies showing risk of bias by ROBINSI), inconsistency (substantial unexplained inter-study heterogeneity, $I^{2} \geq 50 \%$ and $P_{\text {het }}<0.10$ ), indirectness (presence of factors relating to the population, exposures and outcomes that limit generalizability), imprecision [95\% CIs were wide or crossed a minimally important difference of 5\% (SRR 0.95-1.05) for all CVD outcomes] and publication bias [significant evidence of small-study effects). Criteria to upgrade included a large effect size (SRR $>2$ or SRR $<0.5$ in the absence of plausible confounders], a dose-response gradient and attenuation by plausible confounding effects.

\section{Results}

\section{Study characteristics}

Out of 291 initial references identified, a total of 39 studies [16-54] were selected based on 38 cohorts providing data on CHD (1,831,038 individuals and 85,053 cases), stroke (761,962 individuals and 25,103 cases), heart failure (254,588 individuals and 7536 cases), and CVD (1,117,033 individuals and 147,124 cases) outcomes (Fig. 1). A detailed description of the studies included is presented in Table 1. From the 38 individual cohorts, 16 were from North America, 9 from Europe, 9 from Asia and one from Iran, and 3 multinational cohorts. One of the studies from North America included a pooled analysis of 6 US cohorts (pooled data was used in this meta-analysis). All studies had adequate follow-up to assess occurrence of the outcomes investigated (ranging from 3 to 32 years of mean follow-up). All studies scored moderate or serious risk of bias; a detailed description of judgment of potential risk of bias is given in the online supplementary materials (ESM Table 2). All but four studies [25, 28, 32, 34] provided full data of interest for better risk estimation (number of cases and person-years for each category of exposure), most of studies reported analyses adjusted for potential confounders investigated: among other dietary factors, besides total energy intake nearly always considered, also intake of other food groups (fruit/ vegetable, whole grains, meat), macronutrients (trans-fats, protein) and fiber have been considered. Subgroup analyses were conducted through sex- and diabetic-specific groups, including nine studies provided separate risk estimates for 
Fig. 1 Flow chart of study identification and selection process

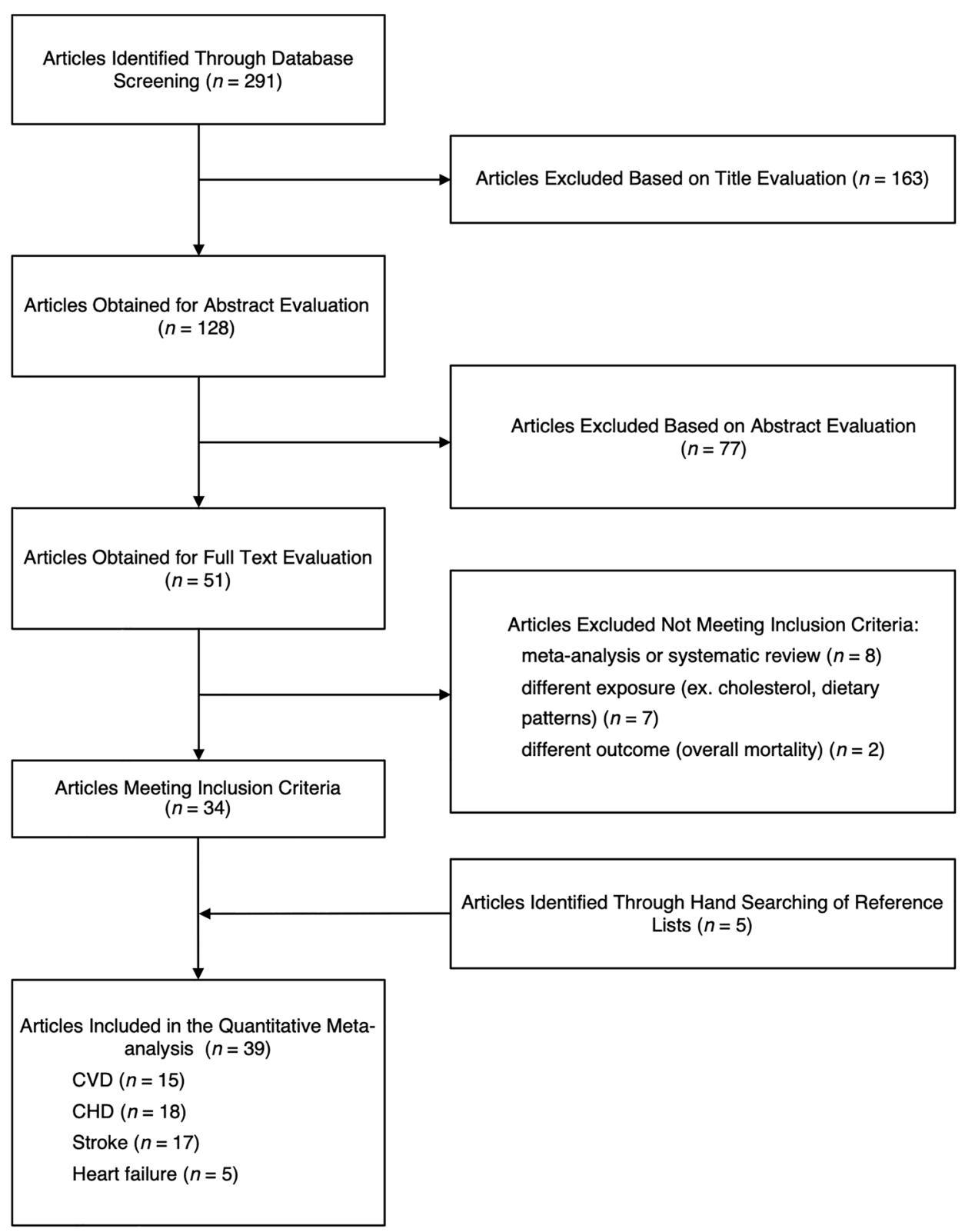

male and female participants, and eight studies for diabetic participants.

\section{Egg consumption and cardiovascular outcomes}

The dose-response analyses for egg consumption and cardiovascular outcomes are showed in Fig. 2. The summary analysis including 17 datasets from 14 studies conducted on CVD (incidence and/or mortality) showed that intake of up to six eggs per week is inversely associated with CVD events, when comparing to no consumption $[\mathrm{SRR}=0.98$ (95\% CI: 0.95; 1.00), SRR =0.96 (95\% CI: 0.91; 1.00), $\mathrm{SRR}=0.95(95 \% \mathrm{CI}: 0.89 ; 1.00), \mathrm{SRR}=0.95(95 \% \mathrm{CI}:$ $0.90 ; 1.00), \mathrm{SRR}=0.95$ (95\% CI: $0.91 ; 1.00), \mathrm{SRR}=0.96$
(95\% CI: 0.92; 1.00) for 1, 2, 3, 4, 5, and six eggs per week, respectively; $\left.\left(I^{2}=71.94 \%, P_{\text {heter }}<0.001\right)\right]$ with no evidence of publication bias $\left(P_{\text {Egger }}=0.772\right)$. The analysis restricted to CVD mortality showed wide confidence intervals while a decreased risk of CVD incidence was observed for consumption of up to 1 egg per day (Table 2).

The summary analysis for CHD incidence/mortality including 24 datasets from 16 studies showed a decreased risk up to two eggs per week $[\mathrm{SRR}=0.96$ (95\% CI: 0.91 ; $\left.1.00), I^{2}=82.25 \%, P_{\text {heter }}<0.001\right]$ compared to no consumption, while higher intake was associated with no further reduced risk; no publication bias was detected $\left(P_{\text {Egger }}=0.173\right)$. Distinction between studies on CHD incidence or mortality showed that the associated reduced risk 


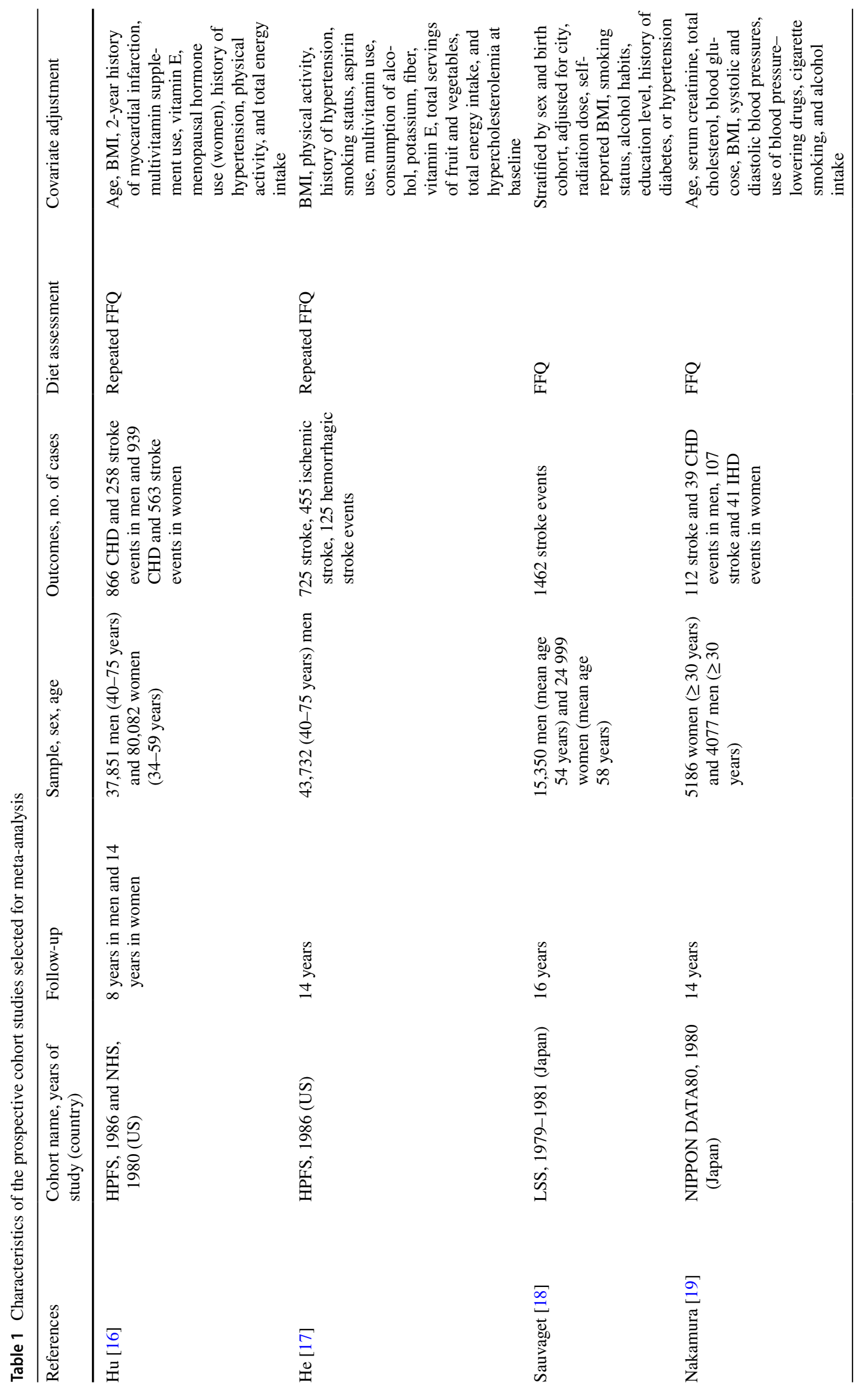




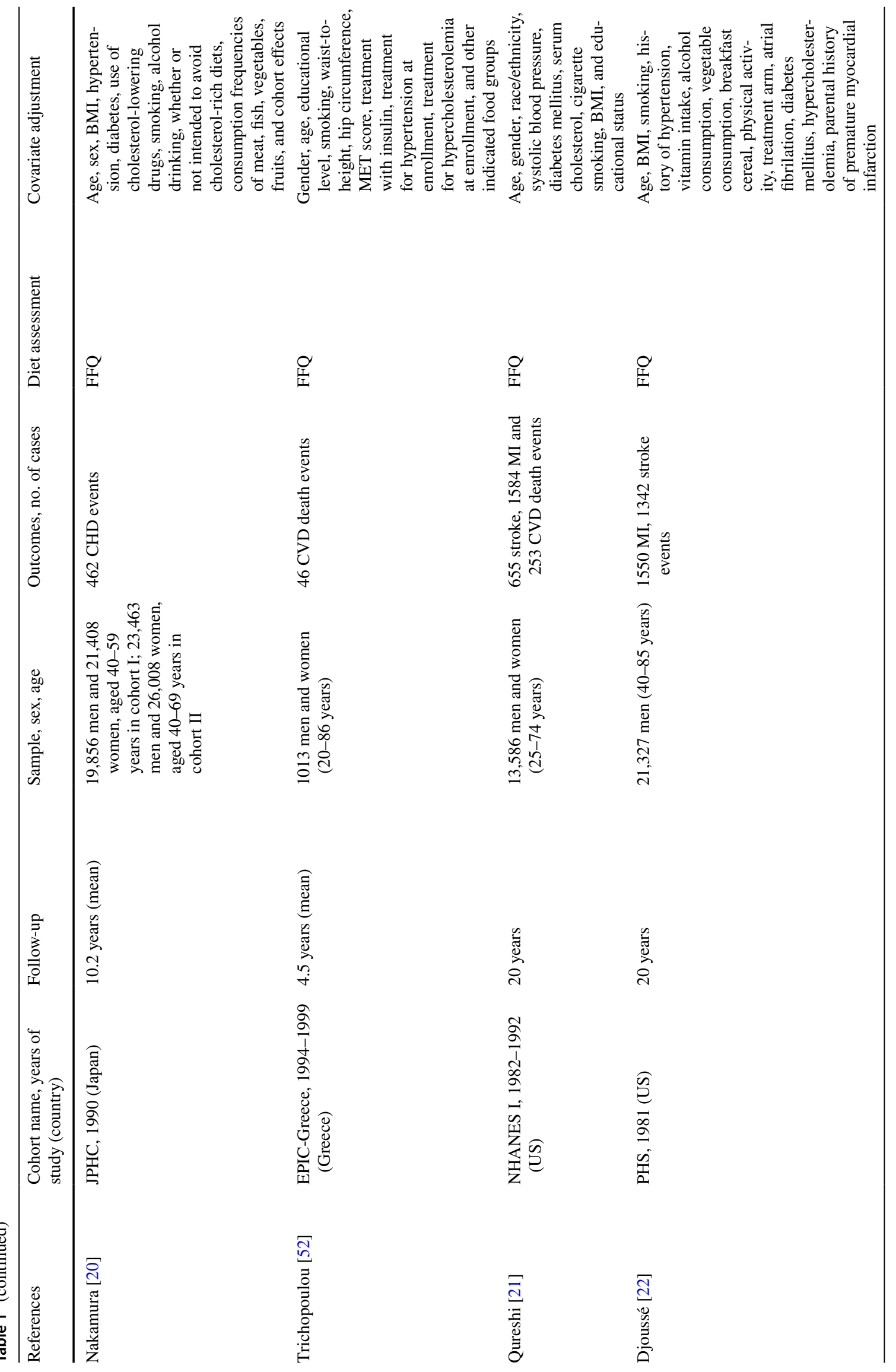




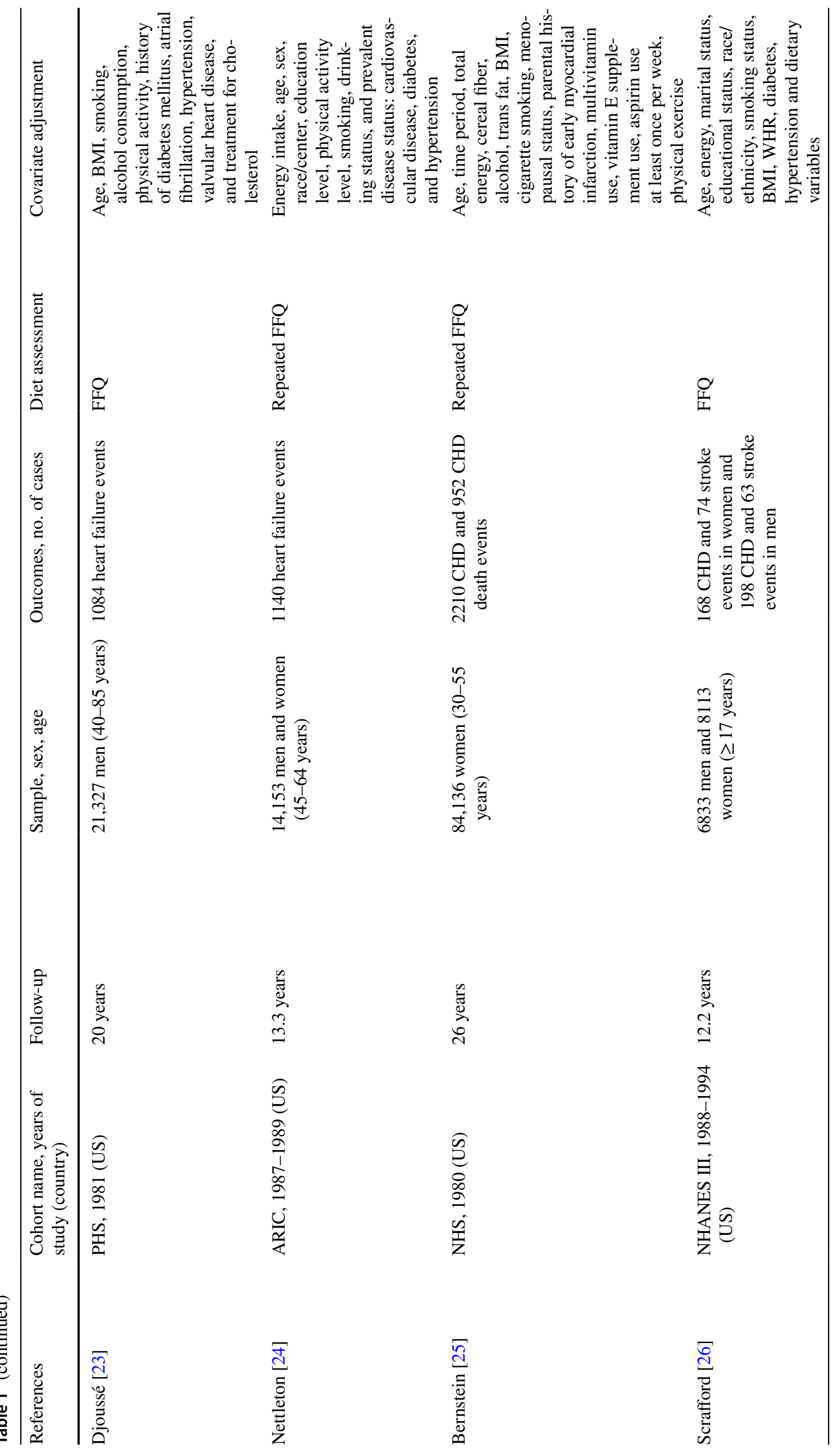




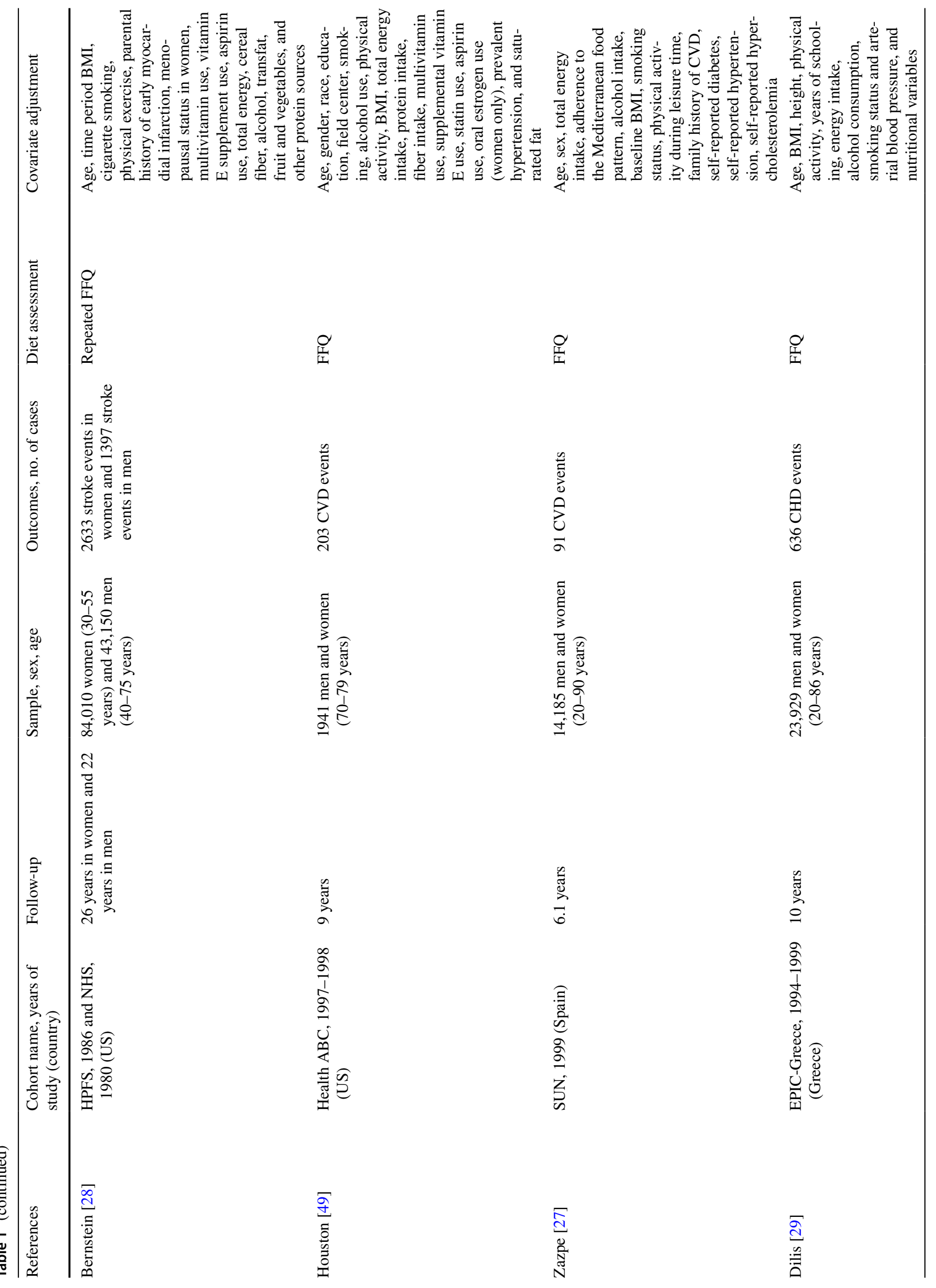




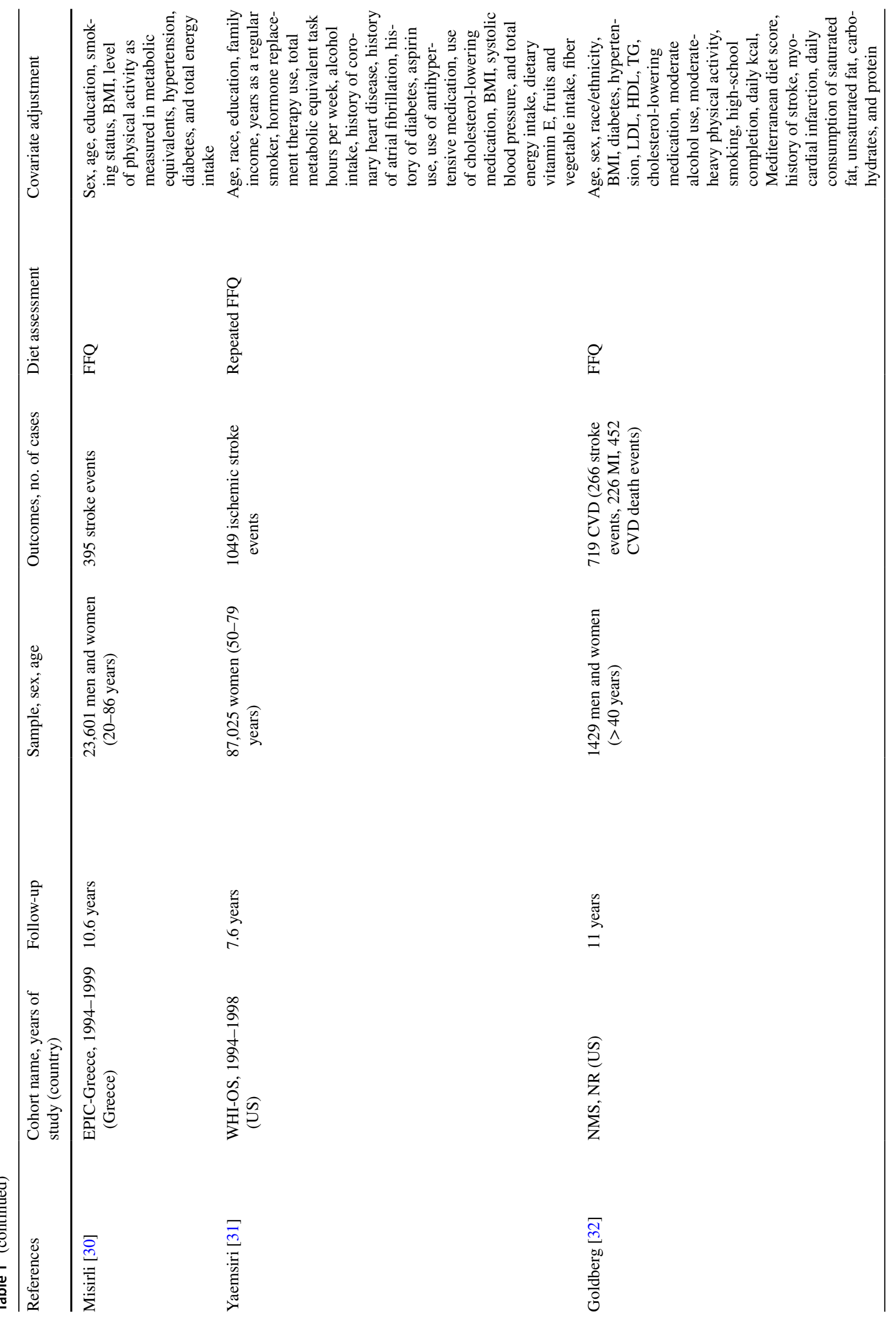




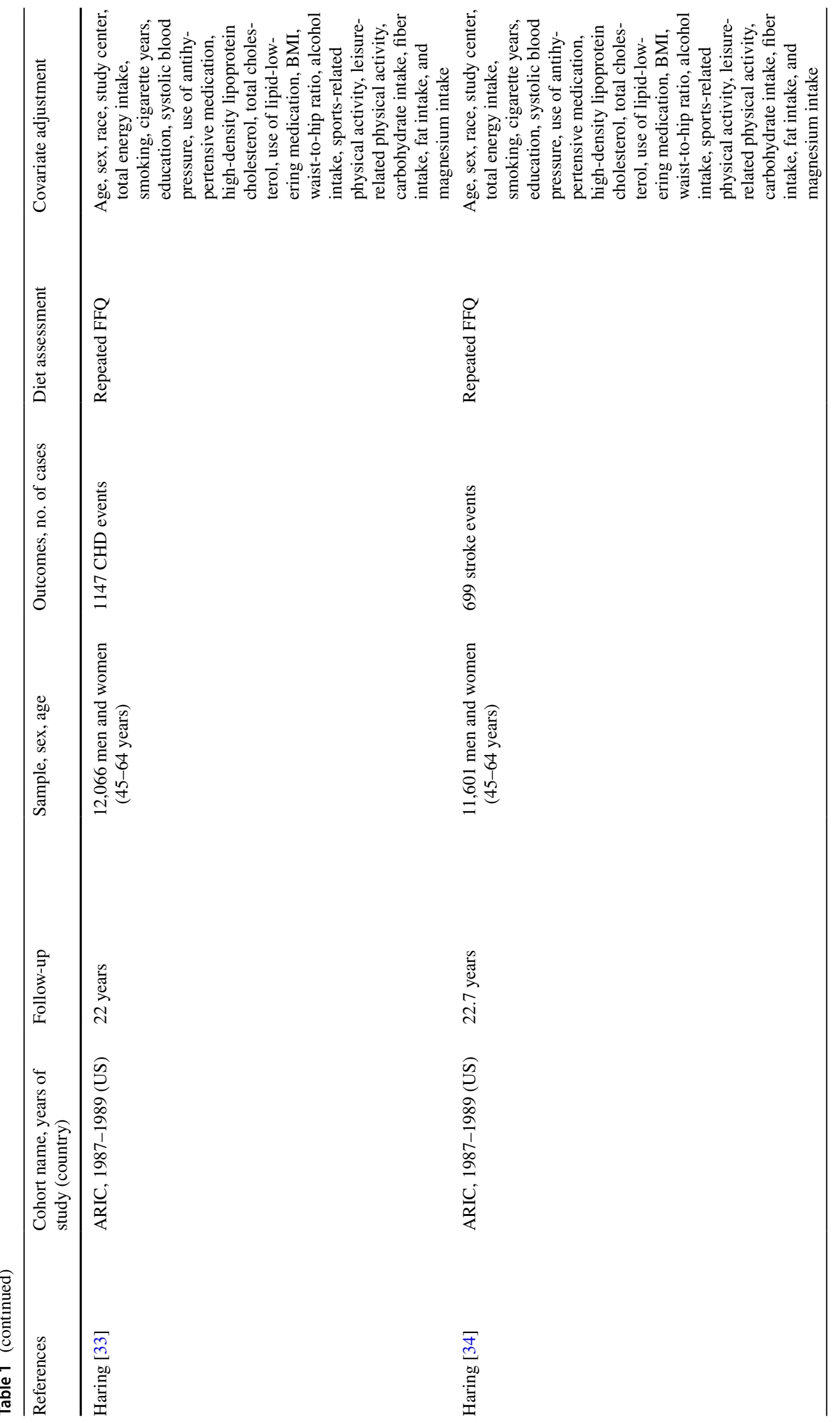




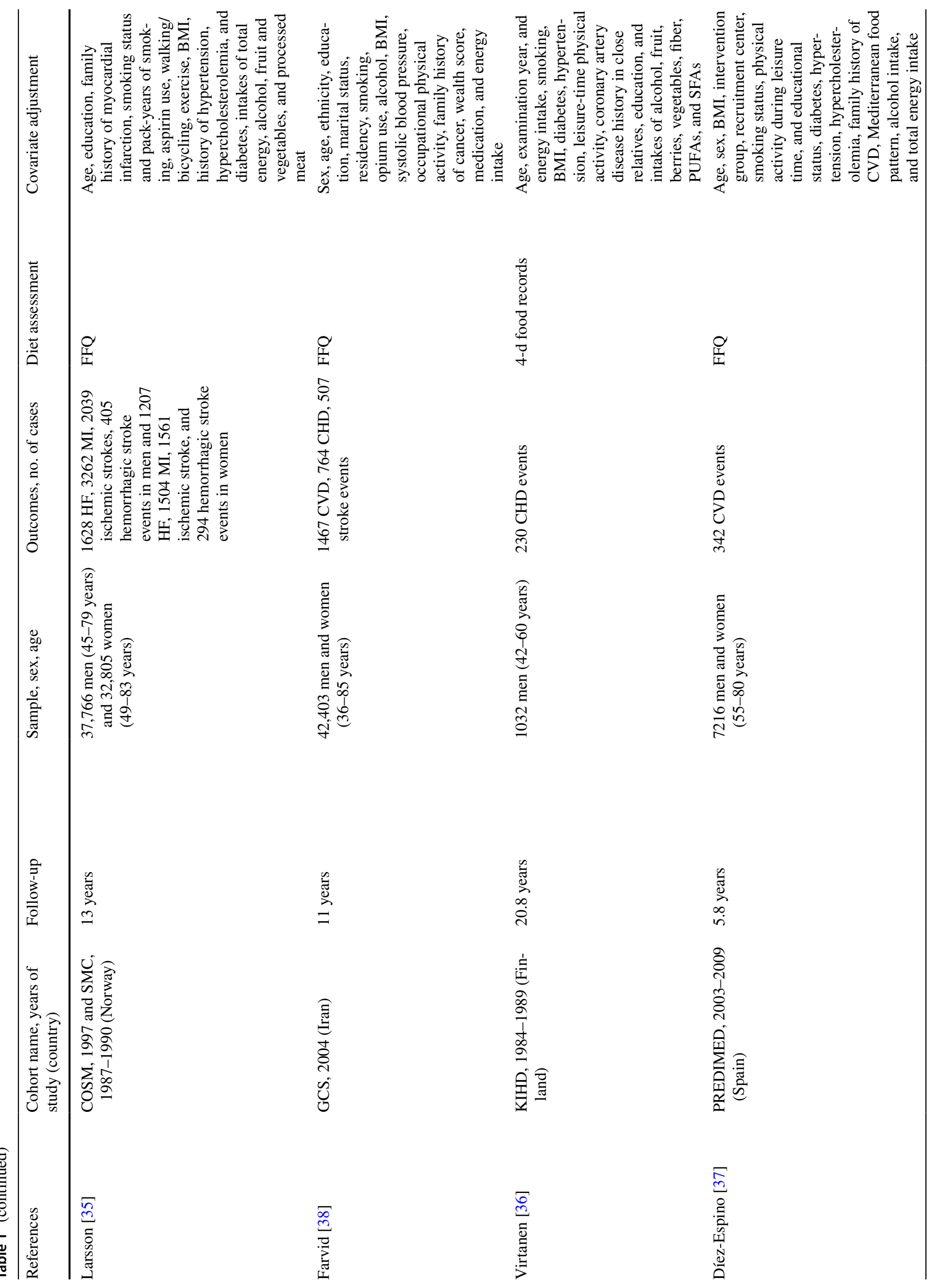




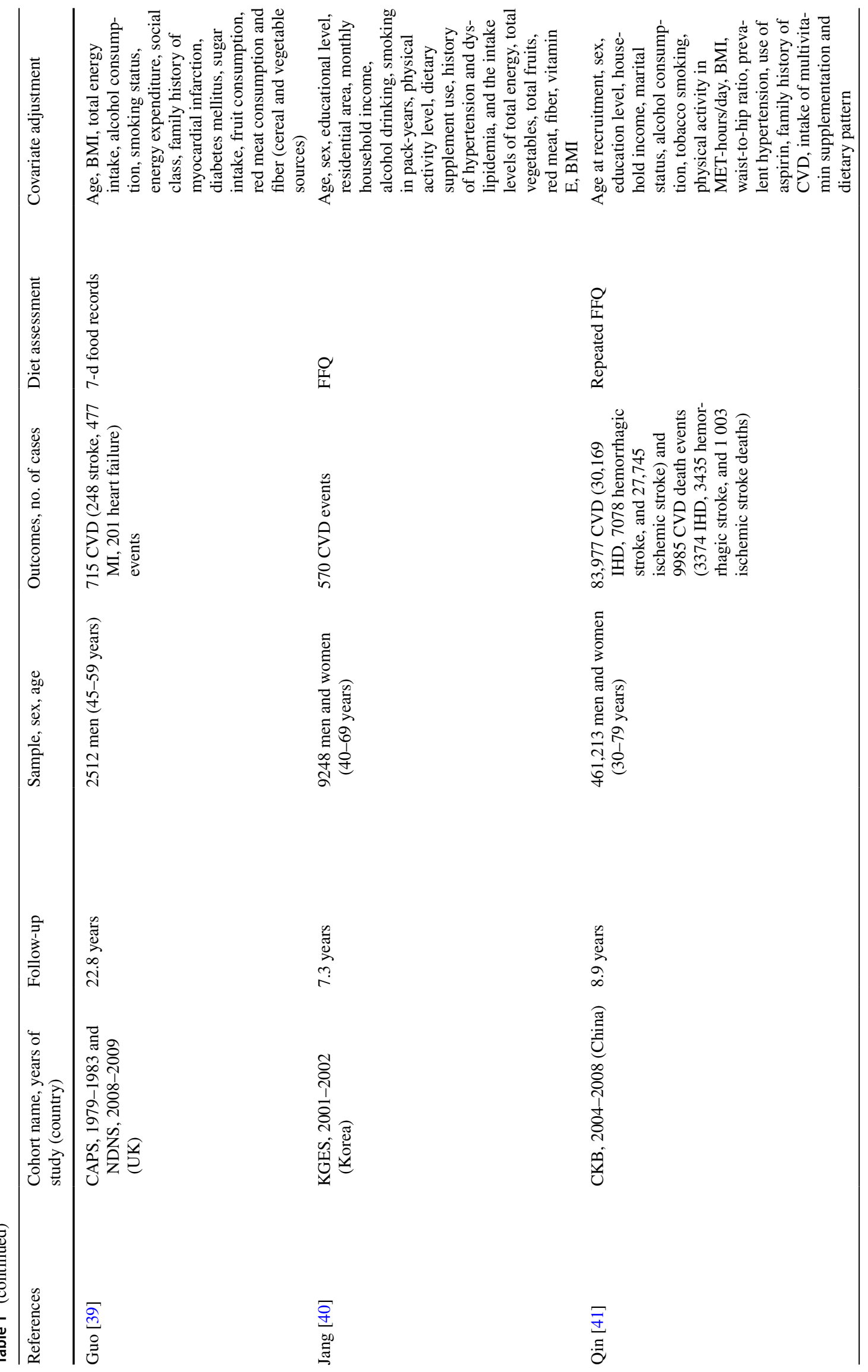




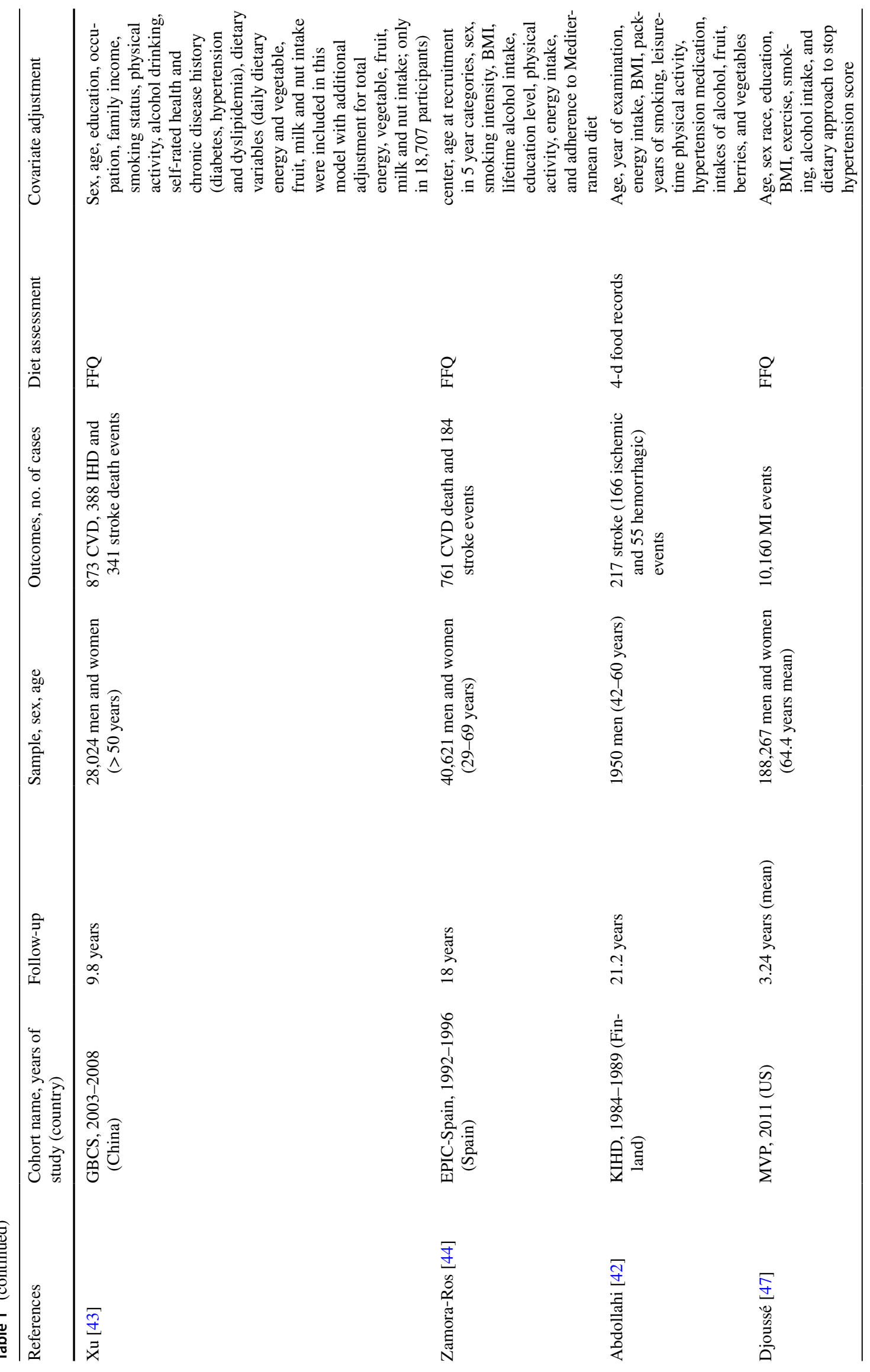




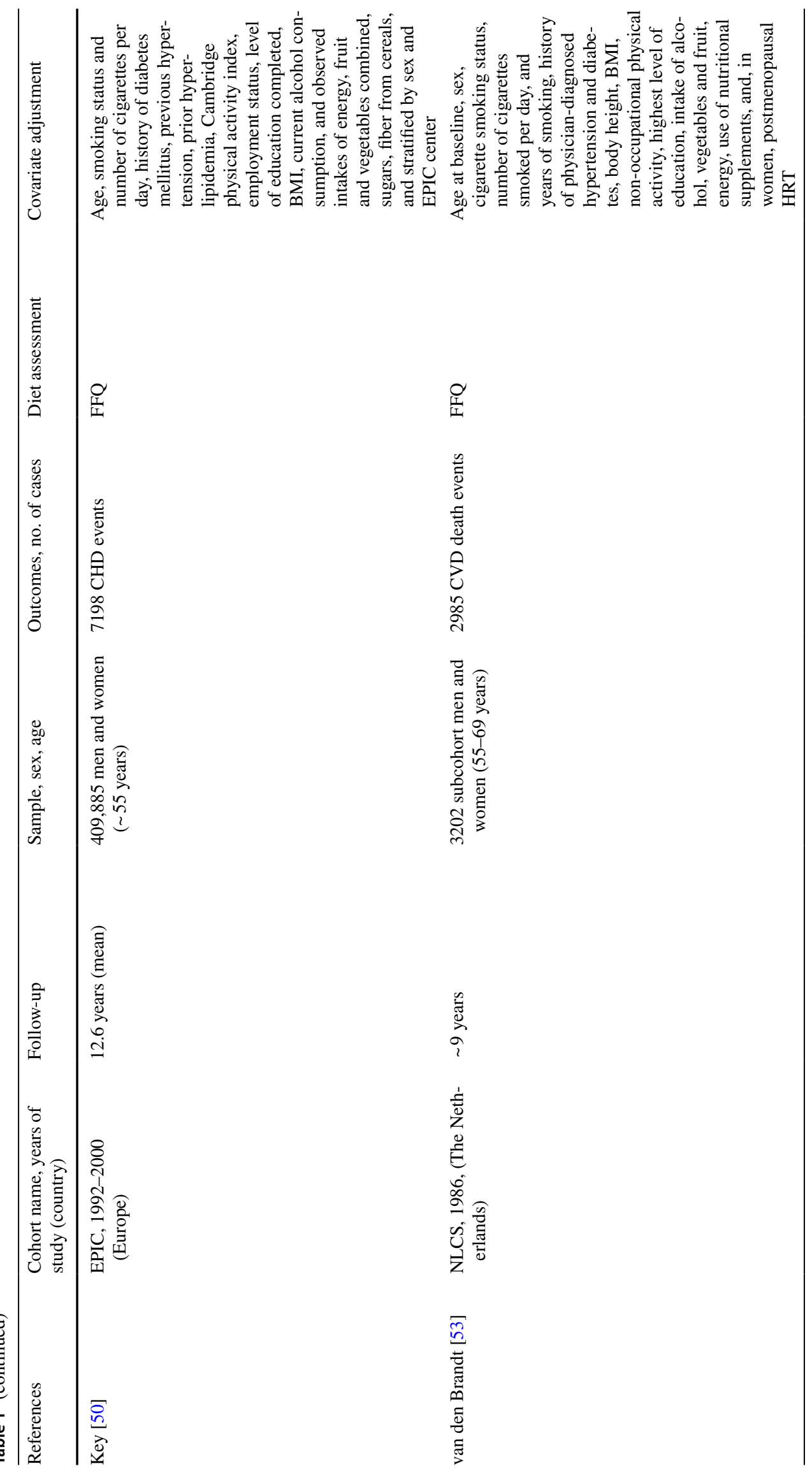




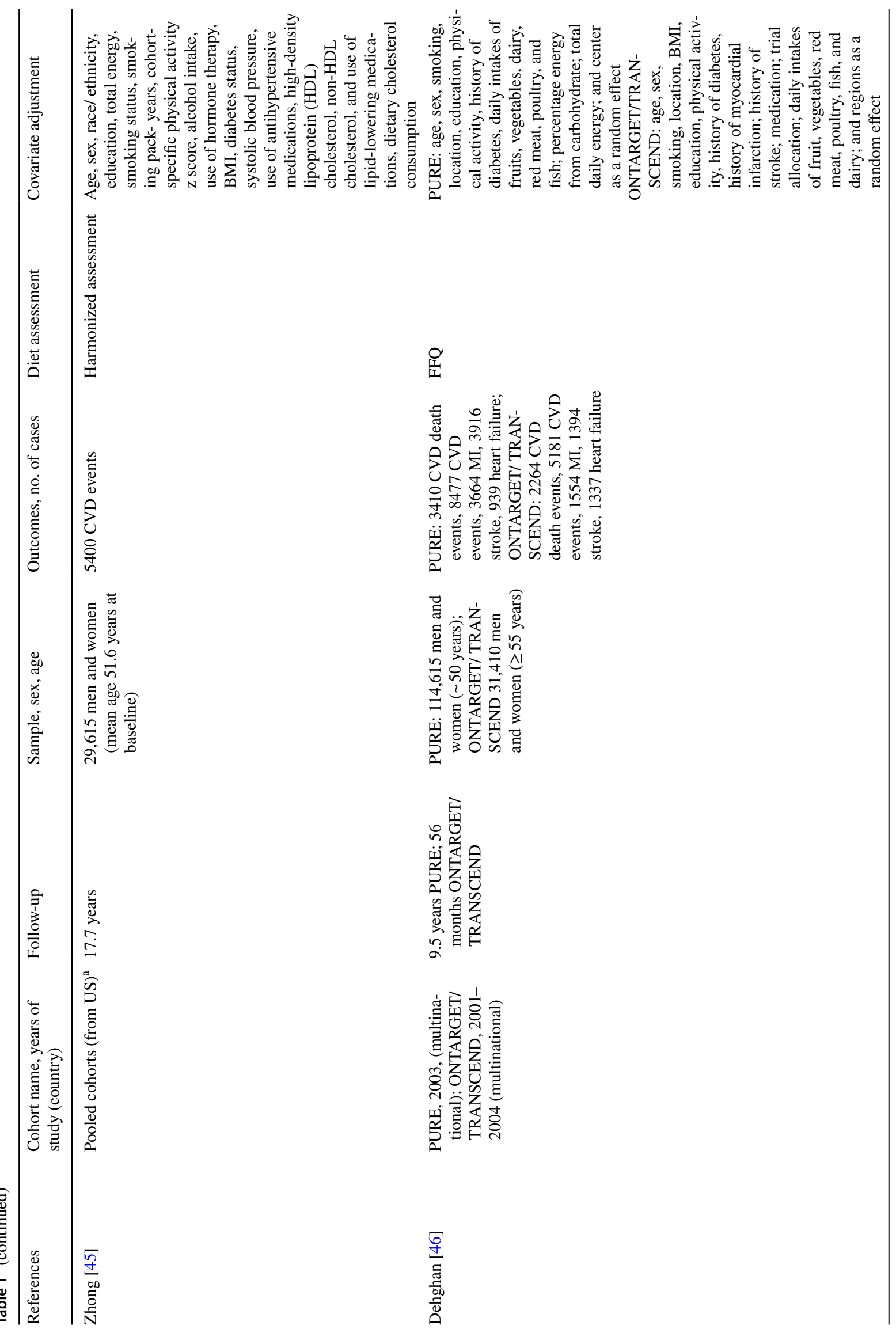




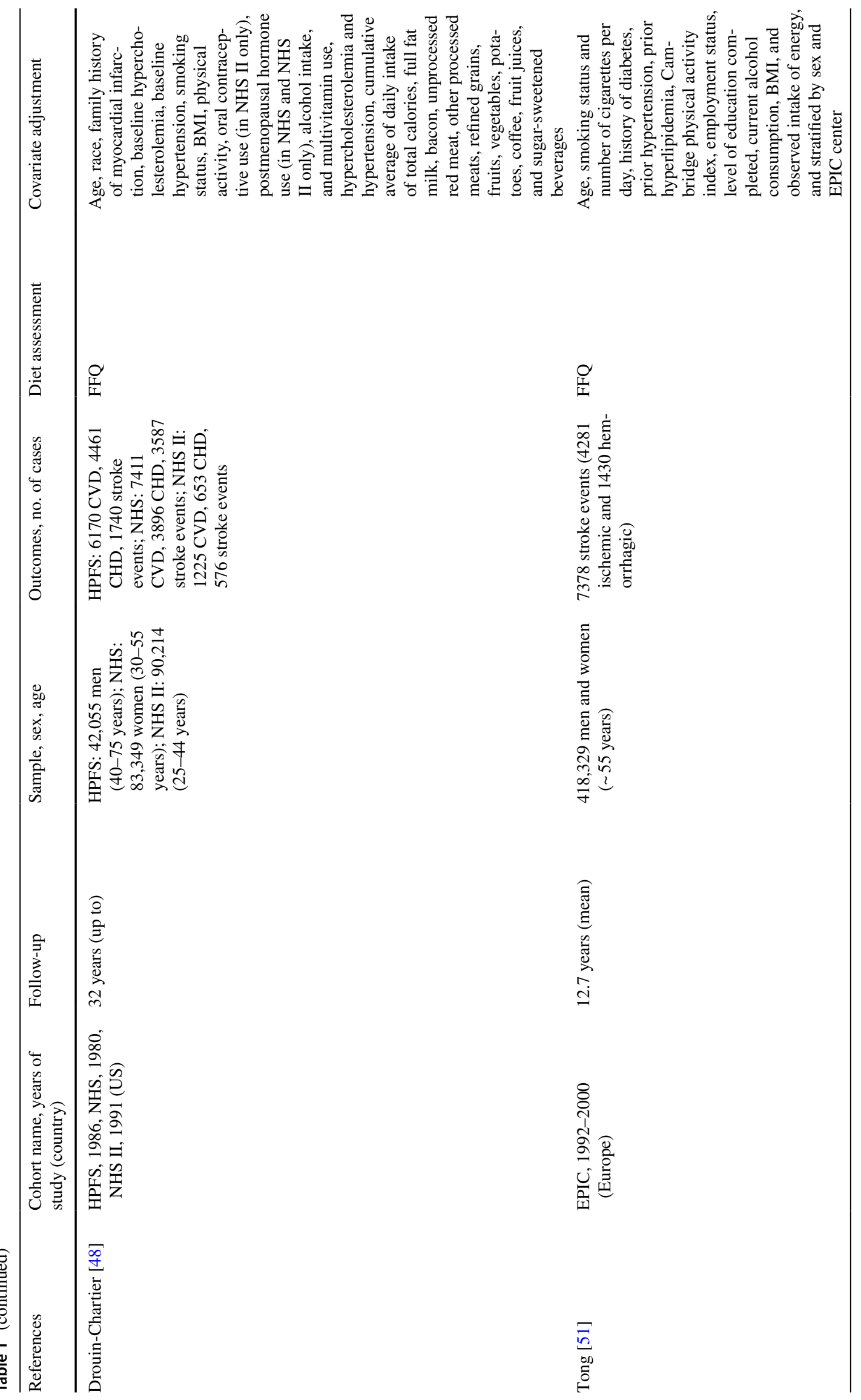




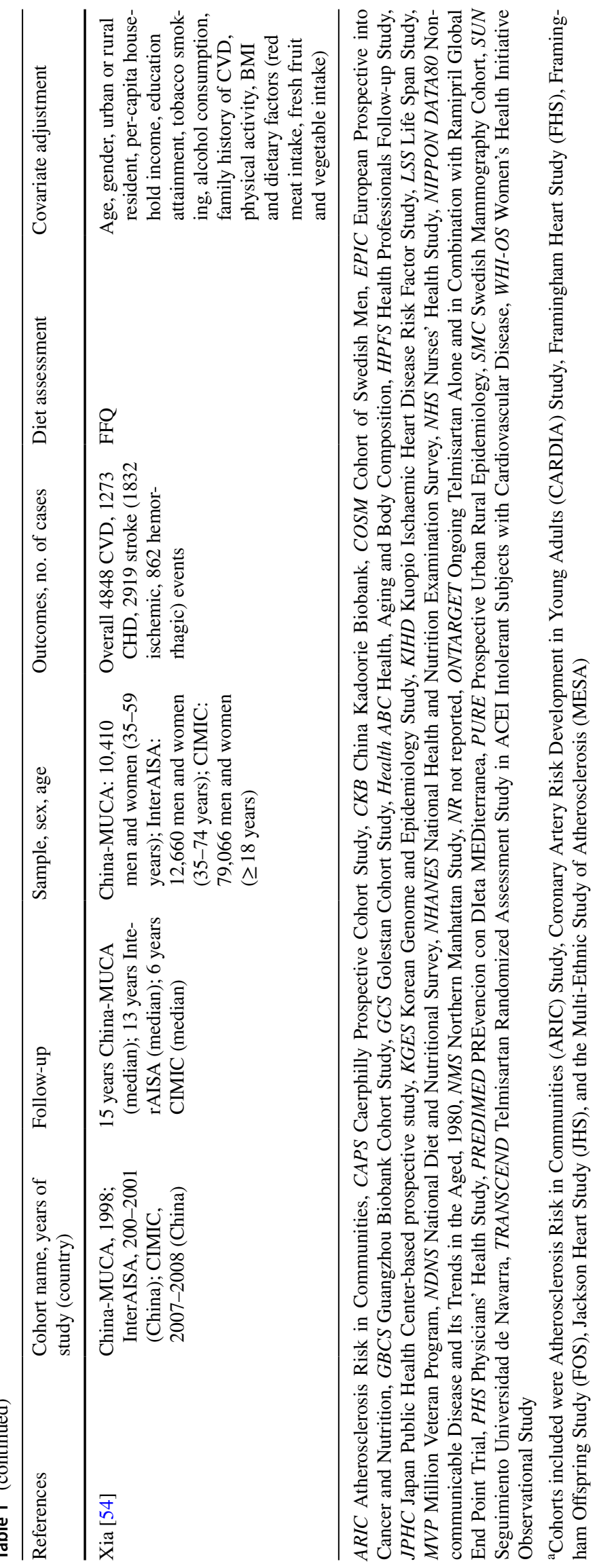


CHD
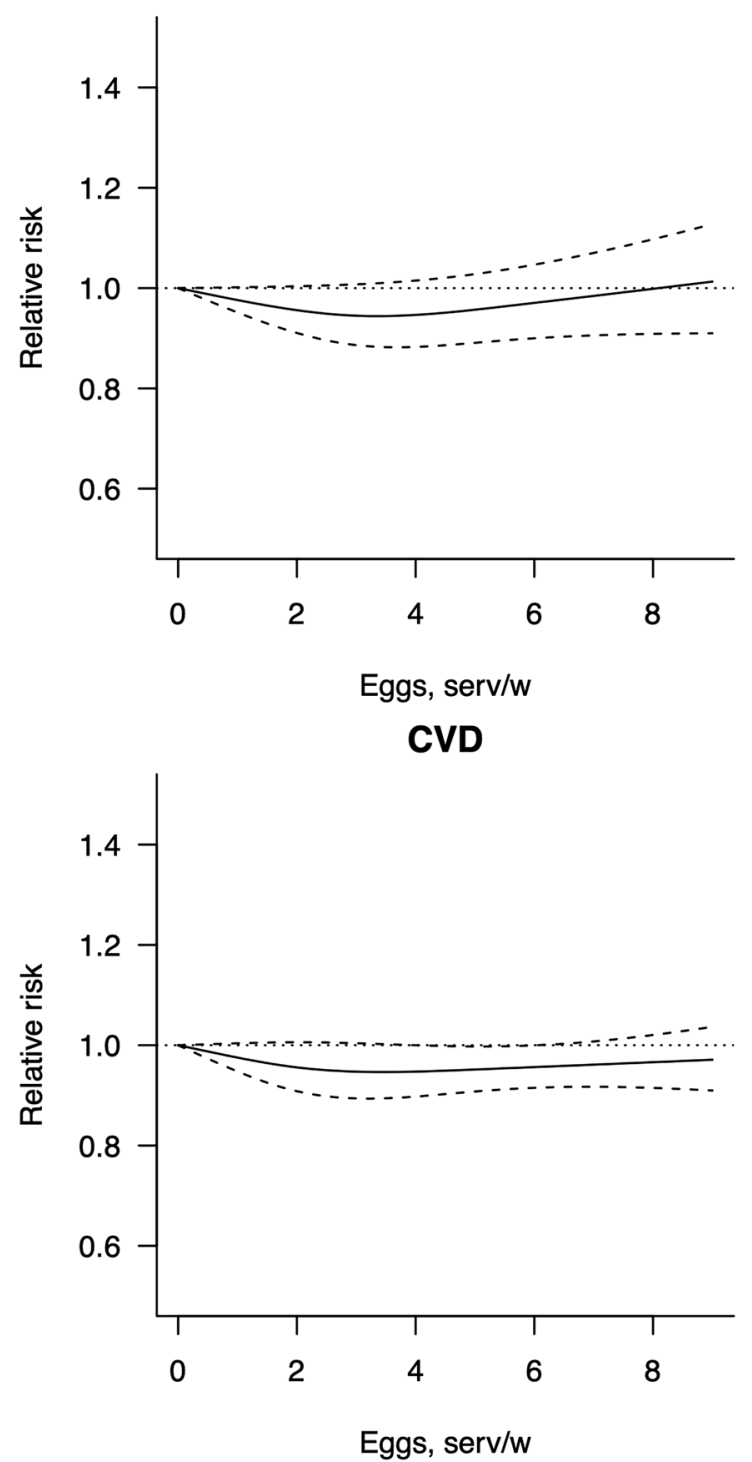

Stroke

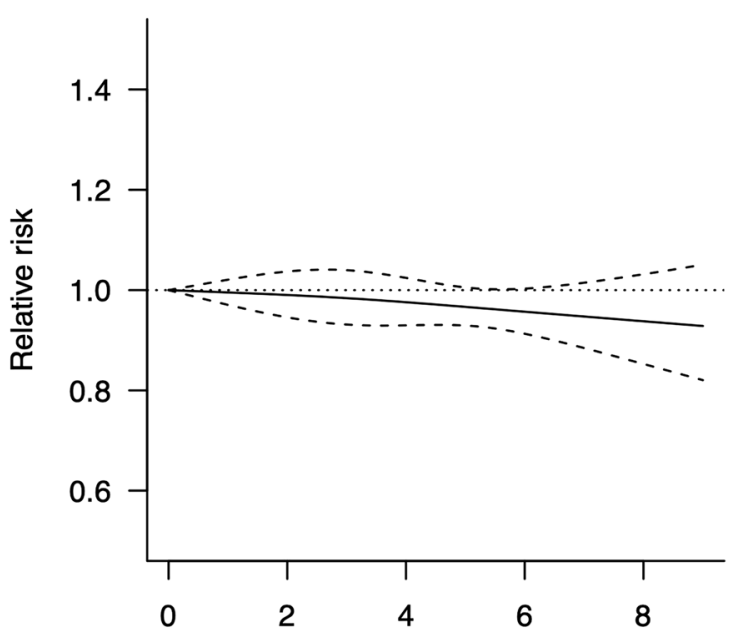

Eggs, serv/w

Heart failure

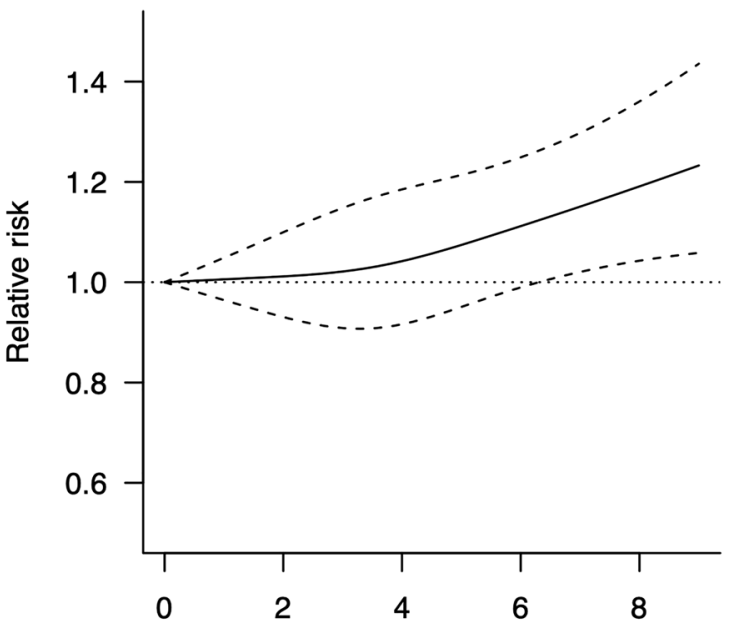

Eggs, serv/w

Fig. 2 Graphical representation of dose-response association between egg intake and CVD, CHD, stroke and heart failure risk in prospective cohort studies

was referring to the former, yet with evidence of heterogeneity (Table 2).

The summary analysis for stroke including 22 datasets from 16 studies showed no related risks associated with any dose of egg consumption compared to no consumption, with lower SRRs for stroke mortality, though with large CIs (Table 2). Also, the analyses conducted on sub-types of stroke, despite investigated in a lower number of studies (eight studies on hemorrhagic and nine studies on ischemic stroke), showed null associations with egg consumption, yet with evidence of heterogeneity (Table 2).

The summary analysis for heart failure risk including six datasets from four studies showed that intake of one egg per day was associated with increased risk raising for higher intakes compared to no consumption [SRR $=1.15$ (95\% CI:1.02; 1.30), SRR $=1.19$ (95\% CI: 1.04; 1.36), $\mathrm{SRR}=1.23(95 \% \mathrm{CI}: 1.06 ; 1.44)$ for 7,8 , and nine eggs per week, respectively], with no evidence of heterogeneity $\left(I^{2}=37 \%\right)$ and no publication bias $\left(P_{\text {Egger }}=0.630\right)$.

In the sensitivity analyses by excluding one study at the time, results were substantially unchanged (data not shown). Also in the sensitivity analyses excluding studies with no complete data on number of individuals and cases risk estimates associated to egg consumption were unchanged for CVD and heart failure, while no associations with CHD and stroke were detected (ESM Table 3); moreover, both ischemic and hemorrhagic stroke risk was 


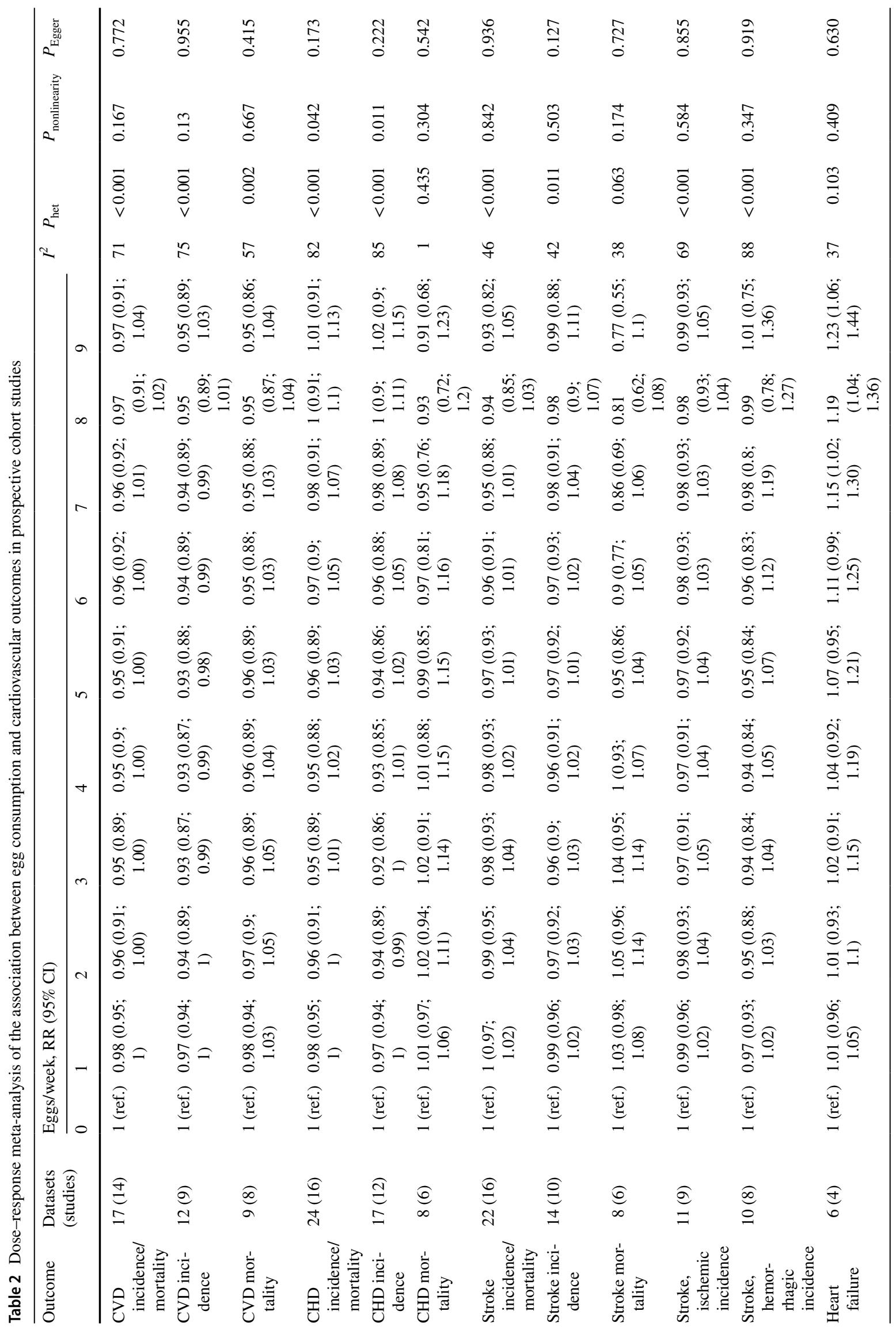


reduced with up to one egg per day compared to no consumption (ESM Table 3).

\section{Subgroup analyses}

The subgroup analysis including results on cohort restricted to diabetic individuals showed that the direction of the risk associated with egg consumption was substantially inverted for all outcomes (Table 3); among all of them, the risk of CVD incidence/mortality peaked up to one egg per day $\left.\left[\mathrm{SRR}=1.22(95 \% \mathrm{CI}: 1.08 ; 1.39), I^{2}=63 \%\right)\right]$ compared to no consumption.

The subgroup analysis by sex revealed a different relation with risk of CVD, CHD, and heart failure in women than in men. Among women a decreased risk of all outcomes for consumption of 4 eggs per week [SRR $=0.89$ (95\% CI: 0.82 ; $0.96)$, SRR $=0.89$ (95\% CI: 0.82; 0.98), and 0.84 (95\% CI: $0.71 ; 1.00)$, respectively] with no evidence of heterogeneity between studies was observed (Table 3 ). When considering consumption of one egg per day, only CVD risk was decreased in women [SRR $=0.90(95 \%$ CI: $0.81 ; 1.00)$ ], with no evidence of heterogeneity $\left(I^{2}=0 \%\right)$ (Table 3 ). No significant associations were observed among men (Table 3 ).

\section{Stratified analyses}

Several stratified analyses have been performed to test the stability of results taking into consideration the geographical localization of the cohorts as well as the level of adjustment models and the quality of the studies included. The analyses have been considered for a moderate consumption (four eggs per week) and a habitual consumption (one egg per day). Concerning the intake of 4 eggs/week, the decreased risk of CVD was confirmed when restricting the analyses to the majority of better quality studies, such as those adjusting for BMI, other dietary factors, longer follow-up, larger sample size, including heart failure in the definition of CVD, and scoring moderate risk of bias (Table 4); other strata associated with a decreased risk of CVD where studies conducted in US cohorts. Similar associations were retrieved for risk of CHD, with a direction toward reduction when restricting the analysis to studies adjusting for other dietary factors, longer follow-up and low risk of bias (Table 4). No association between moderate egg consumption and risk of stroke nor heart failure was found (Table 4).

Concerning the intake of $1 \mathrm{egg} / \mathrm{day}$, the analysis resulted in a decreased risk of CVD when involving studies conducted in Asia and adjusting for other dietary factors (Table 4); curiously, a decreased risk was also observed in studies not adjusting for diabetic status, which on the contrary was reported to potentially act as effect modifier toward the opposite direction. No associations were retrieved for CHD risk, while also the risk of stroke was reduced only when considering Asian cohorts and studies including more than 10,000 individuals (Table 4). Also risk of heart failure differed between strata, resulting higher in the analysis restricted to US cohorts with large sample size, adjusted for BMI but not for other dietary factors; no study with low risk of bias was available (Table 4).

\section{Evaluation of the evidence}

Table 5 provides an overview of the GRADE assessment for the association between consumption of eggs and each cardiovascular outcome. The level of evidence was rated generally low for all outcomes but stroke, for which was moderate.

\section{Discussion}

The present meta-analysis provided an updated overview on the association between egg consumption and CVD risk and mortality: compared to previous meta-analyses, we included the highest number of cohorts reviewed to date, several dose-response analyses for the investigated outcomes, a detailed investigation for potential confounding factors by studying subgroups and stratifying the analyses, and we attempted an evaluation of the overall evidence. Previous meta-analyses reported rather mixed results, with no association with stroke risk [55], decreased risk of stroke and no association with CHD [56, 57], decreased risk of CHD [58], no association with CVD risk [59], increased risk of heart failure $[60,61]$,compared to these studies, our analysis is more complete and provides a general more in depth analysis of level of evidence. We generally found no strong association with either increased or decreased risk of cardiovascular outcomes following the habitual consumption of eggs (i.e., one egg per day compared to no intake), with exception of risk of heart failure, which resulted higher especially in men from US cohorts. In contrast, there are more consistent results regarding the association between moderate egg consumption (i.e., four eggs per week compared to no intake) and lower risk of CVD, especially in spite of the stratified analyses involving higher quality studies, for which there was lower heterogeneity across results. Also when considering the findings from the stratified analyses, heterogeneity of the results between studies remained significant and rather unexplained. We can hypothesize that egg consumption between men and women or across different geographical areas may be associated with unmeasured lifestyle choices or in the context of different quality of the overall diet to motivate the differences observed in these strata, another hypothesis is that these strata may also reflect genetic unmeasured factors motivating the inter-individual variations. After the GRADE assessment, we could not 


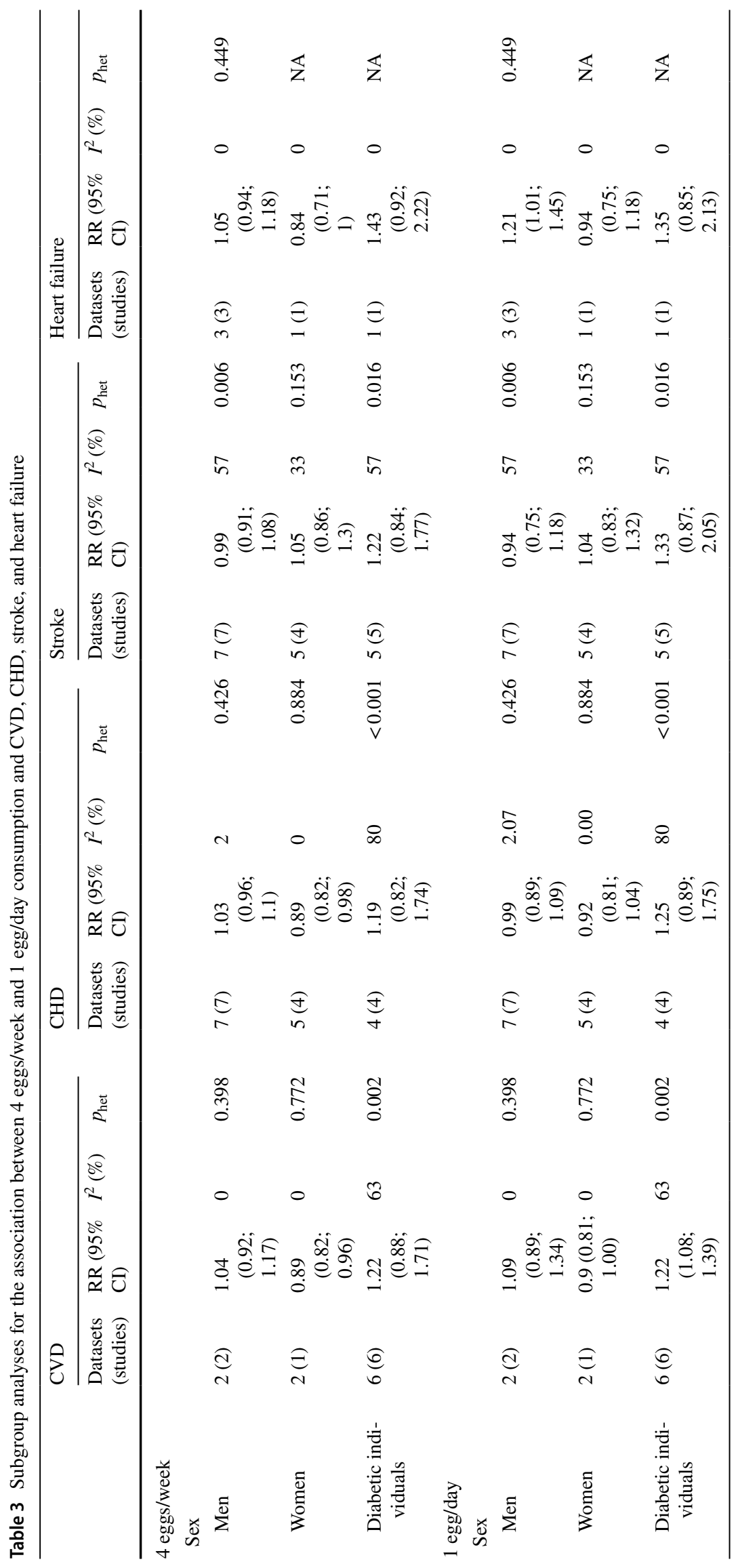




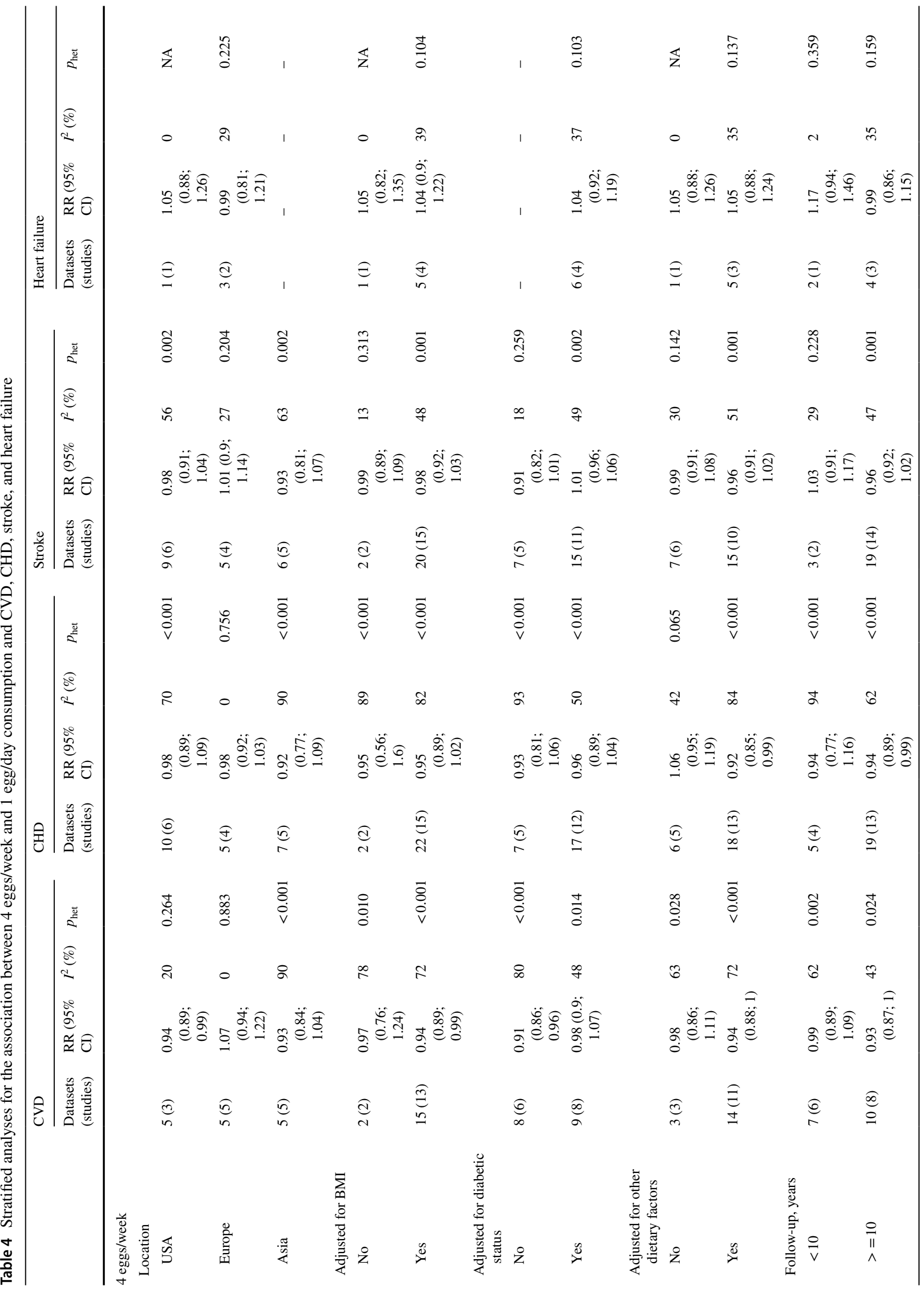




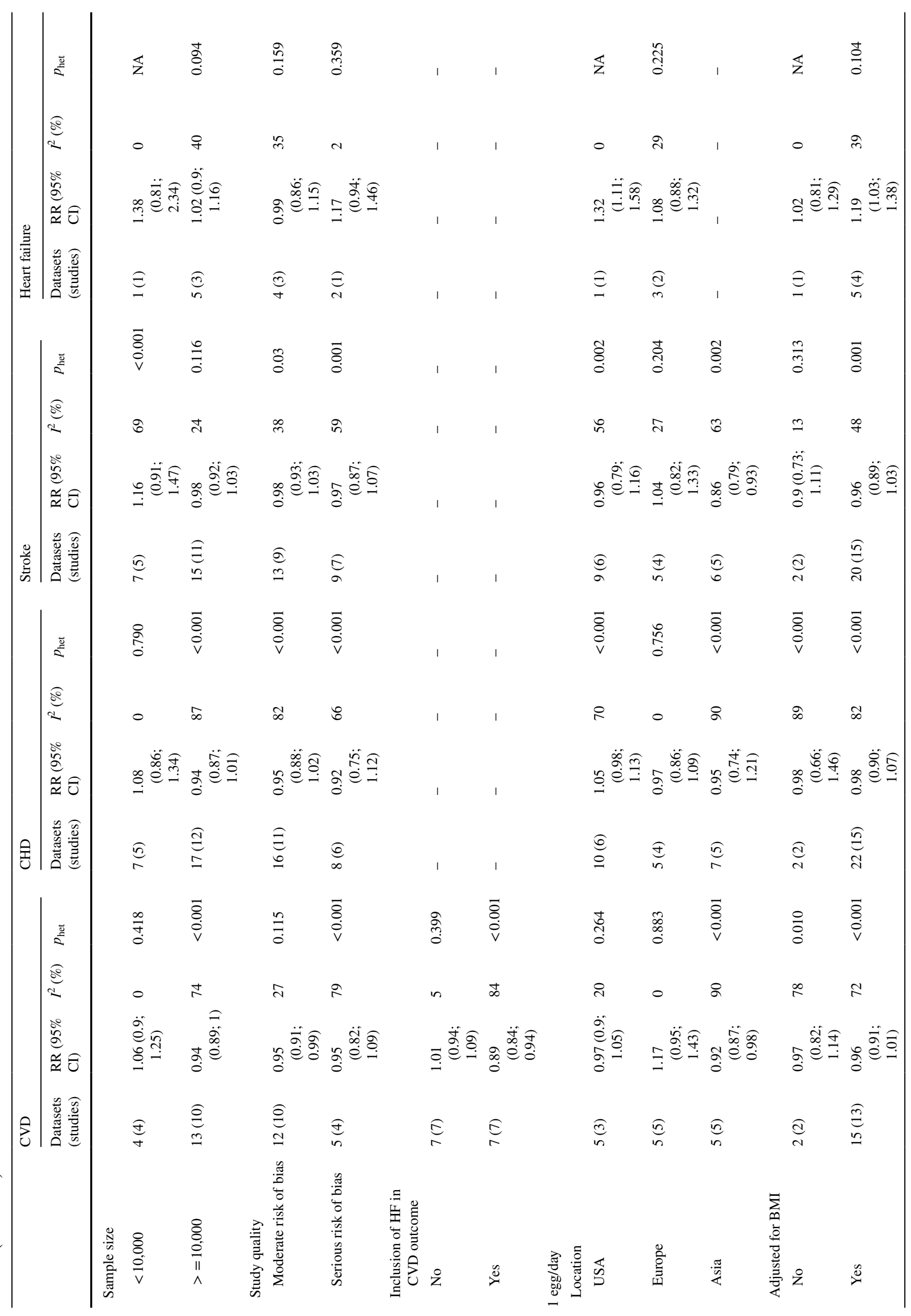




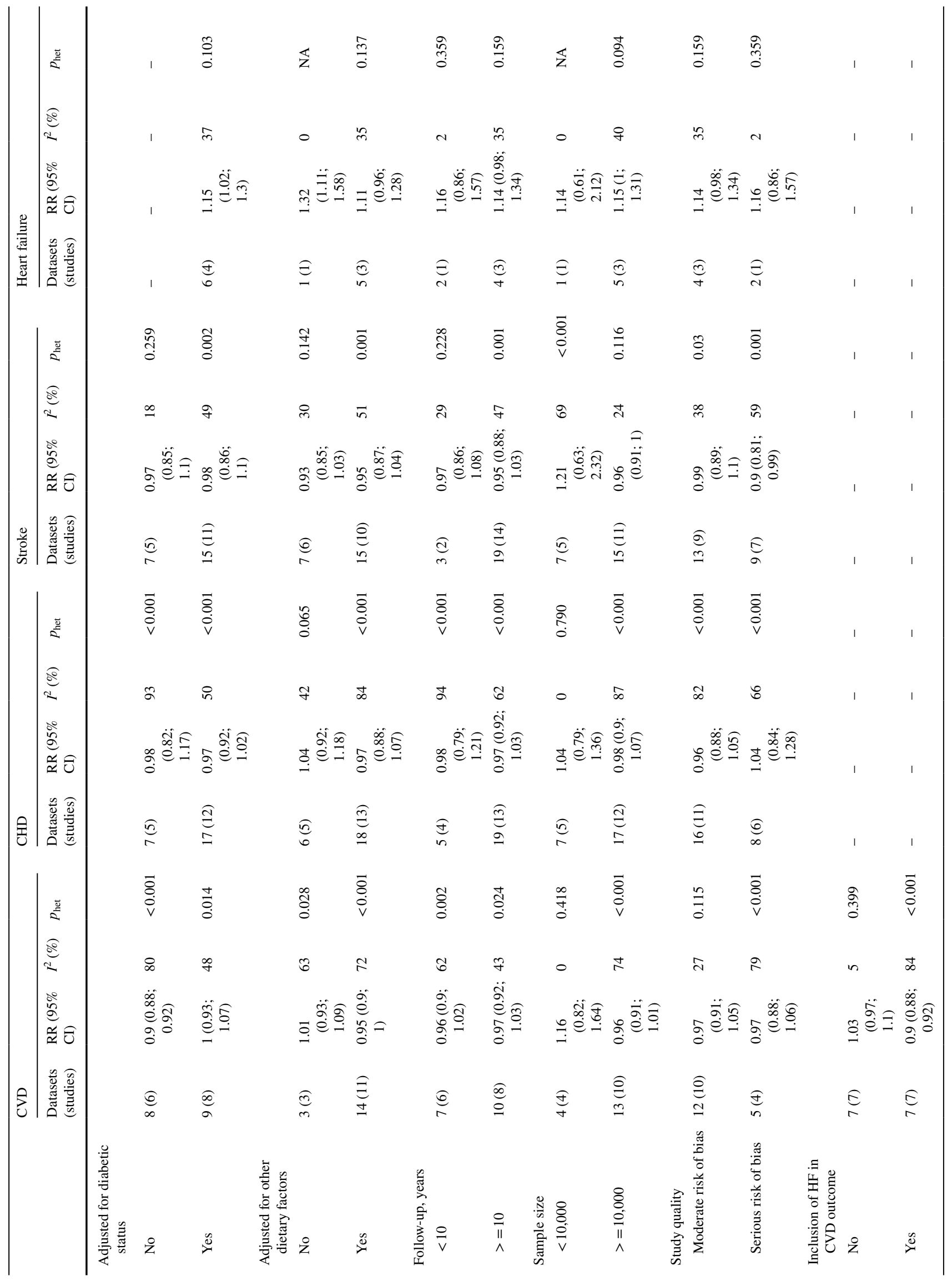


Table 5 Certainty of evidence by GRADE criteria

\begin{tabular}{|c|c|c|c|c|}
\hline & CVD & CHD & Stroke & Heart failure \\
\hline No. of studies & $17(14)$ & $24(16)$ & $22(16)$ & $6(4)$ \\
\hline \multicolumn{5}{|l|}{$\begin{array}{l}\text { Downgrade quality of } \\
\text { evidence }\end{array}$} \\
\hline Risk of bias & No & No & No & No \\
\hline Inconsistency & Yes & Yes & No & No \\
\hline Indirectness & No & No & No & Yes \\
\hline Imprecision & No & No & No & No \\
\hline Publication Bias & No & No & No & No \\
\hline \multicolumn{5}{|l|}{$\begin{array}{l}\text { Upgrade quality of } \\
\text { evidence }\end{array}$} \\
\hline Large effect & No & No & No & No \\
\hline Plausible confounding & $\mathrm{No}^{\mathrm{a}}$ & $\mathrm{No}^{\mathrm{a}}$ & No & No \\
\hline Dose-response & Yes $^{\mathrm{b}}$ & No & Yes $^{\mathrm{b}}$ & Yes $^{\mathrm{b}}$ \\
\hline $\begin{array}{l}\text { Overall quality of evi- } \\
\text { dence }\end{array}$ & Low & Low & Moderate & Low \\
\hline
\end{tabular}

${ }^{a}$ Despite better quality studies provided less heterogeneity across results

${ }^{\mathrm{b}}$ The analyses showed no evidence for non-linearity of associations

conclude that exist strong evidence of association between egg consumption and CVD outcomes, but higher quality studies showed a decreased risk of CVD for moderate intake of eggs (four per week), while higher risk of heart failure was found for higher intake of egg (one per day). Interpretation of these findings is not easy: consuming up to four eggs per week may decrease the risk of CVD but increasing the intake to one egg per day or more may not be beneficial anymore. Nonetheless, we cannot exclude that the pattern of the diet and way of cooking might differ depending on the frequency of consumption (i.e., individuals with moderate egg consumption may include eggs into specific recipes varying the way of cooking while habitual consumers may have fried eggs for breakfast together with bacon or other unhealthy dietary features). Such hypothesis could explain the different risks associated with egg consumption in Western and Eastern Asian countries. This is a common issue for nearly all food groups when investigating the relation of one single dietary element with health. However, we cannot ignore that an association can be observed and, in that case, needs further attention.

There is a biological rationale to explain how moderate egg consumption might be associated to decreased risk of CVD. Eggs have been historically considered a controversial food for nutritional experts and health agencies due to its content in cholesterol. However, researchers argue that the focus of common dietary guidelines on specific nutrients (i.e., saturated fats) do not take into account that health effects varies depending on the specific food source [62]. Furthermore, the major attention paid to egg consumption has been based on the assumption that higher dietary cholesterol intake would lead to rise in blood cholesterol, despite current evidence suggests otherwise [63, 64]. Recent meta-analyses showed rise of both LDL and HDL following egg consumption in healthy individuals, with minimum rise of LDL:HDL ratio (marker of CVD risk) finally leading to no substantial increased risk profile [63, 64]. Thus, the concomitant rise of HDL cholesterol might counteract the elevation of LDL, while other components of egg might exert potential beneficial effects [65]. Eggs are a highly nutritious food providing quality proteins and supplying micronutrients, antioxidants, antimicrobials, accompanied with great culinary versatility, which may have potential benefits to overall health. Some egg proteins, such as phosvitin, ovotransferrin and ovalbumin can inhibit lipid oxidation by binding to metal or scavenging free radical [66]. In addition to protein, eggs also contain a large number of active lipid components, such as unsaturated fatty acids, phospholipids, choline, and carotenoids. Eggs are considered a valuable source of omega- 3 polyunsaturated fatty acids, which have been considered to exert a number of health benefits, including CVD protection [67]. Eggs are a major source of choline, an essential nutrient with critical roles in several biological processes including neuronal development, cell signaling, and lipid transport and metabolism [68]. Part of the choline may undergo conversion to trimethylamine by gut microbiota, which in turn is oxidized in the liver to trimethylamine- $N$-oxide (TMAO), agent associated with increased atherosclerosis in the coronary vasculature [69]. Double blinded clinical trial investigating the effect of 0 to 6 egg yolks ingested for the breakfast demonstrated that consumption of $\geq 2$ eggs results in an increased formation of TMAO yet not accompanied by a rise in hsCRP and oxidized LDL levels [70]. Phospholipids contained in eggs, including phosphatidylcholine, phosphatidylethanolamine, lysophosphatidylcholine, sphingomyelin, and some neutral lipids in minor quantities, may have, among others, broad effects on cholesterol metabolism, HDL functions, and inflammation [71]. Egg yolks are also a dietary source of bioavailable xanthophyll carotenoids, such as lutein and zeaxanthin, that have been shown to exert potential benefits against inflammation and oxidation during early development, childhood, and may have lifetime consequences in determining health or onset of major diseases in the adult life [72].

Despite the evidence reported, nearly all analyses showed substantial heterogeneity of results between studies, leading to a weakening of the evidence. We hypothesize that the certain inconsistency of the results may depend on the variability of response to dietary cholesterol between individuals and the overall dietary and lifestyle framework within populations and individuals. Despite the majority of population experience moderate to no difference in blood cholesterol following the intake of dietary cholesterol (consequently described as "normal responders"), about a third 
of individuals suffer of an abnormal rise in circulating LDL cholesterol (thus described as "hyper responders") as a result of an increase fractional absorption and/or endogenous cholesterol synthesis in response to dietary cholesterol intake [73]. An abnormal response to dietary cholesterol has been hypothesized to depend on altered cholesterol transport due to decreased levels of apolipoprotein $\mathrm{E}$ and increased of apolipoprotein C-III [74, 75]. Some genes responsible for intestinal absorption and biliary secretion of cholesterol and phytosterols, such as expression of ATP-binding cassette (ABC) transporters G5 (ABCG5) and G8 (ABCG8) [76], have been proposed as candidates for better understanding of potential genetic influences on egg metabolism. These genetic variants might provide the rationale, at least in part, for the geographical and sex differences observed in this study: however, further studies are warranted to identify other genetic markers that may explain the observed variability in cholesterol absorption/production among the general population.

The results of this meta-analysis on heart failure seems to provide indication of potential increased risk for habitual consumption (one egg per day) despite this evidence was affected by some limitations, including the role of sex: while sex seems to act as confounding factor for CVD, the observed variation in the direction for risk heart failure (increased in men and decreased in women) may lead to consider sex as an effect modifier. The reasons for such finding is not clear. The role of cholesterol abnormalities and risk or worsening of heart failure is unknown; data on worsening heart failure and lipid moieties are now beginning to emerge but conclusions are far to be made [77]. The fact that heart failure was the only outcome potentially at higher risk following consumption of eggs suggests that alternative mechanisms could be responsible for the observed association. Interpretation of these differences between sexes makes even harder to provide a rationale for this result: as suggested in the individual studies included in the meta-analysis, it may be possible that the observed difference between sexes may depend on the fact that men might be more sensitive to high consumption of eggs (or cholesterol) than women, or it could be mediated by uncontrolled risk factors associated with egg consumption (i.e., bacon) occurring more in men than women. Another hypothesis is that individuals more sensible to dietary cholesterol presenting blood lipids abnormalities may be regular users of statins, which in turn are known to increase the risk of atherosclerosis and heart failure by promoting arteries calcification and inhibiting the biosynthesis of selenium containing proteins, respectively [78]: this might explain the mixed results for CHD risk and increased risk of heart failure.

Another concern regard the different risk estimates observed in diabetic individuals showing an increased risk of CVD associated with consumption of one egg per day, notably in the different direction than for the general population. The increased risk of developing CVD among individuals with type 2 diabetes may be mainly attributed to the impaired cholesterol absorption and synthesis. Studies on type 2 diabetic patients with uncontrolled hyperglycemia showed higher cholesterol synthesis and plasma lipid concentrations [79], including total cholesterol and triglyceride, suggesting unfavorable effects of egg consumption on lipid profiles and, consequently, CVD risk. The mechanism might be explained, at least partially, by a reduced plasma level of campesterol, a marker of cholesterol absorption, and increased plasma levels of lathosterol, a marker of cholesterol synthesis among diabetic people [80]. Moreover, apolipoprotein E polymorphism has been associated with higher risk of diabetes, and thus diabetic individuals tend to have lower serum levels of apolipoptorein E and impaired lipid transport [81].

The findings reported in this study should be considered in light of some limitations. First, some analyses showed substantial heterogeneity: several reasons for such discrepancy of results across studies have been aforementioned, but no firm explanation can be drafted at this moment due to lack of data. Second, we stratified the analyses testing the role of controlling for potential confounding factors known to be related to cardiovascular outcomes in the original studies and revealed the importance of conducting higher quality studies to observe a decreased risk of CVD associated with moderate egg consumption; however, we cannot rule out the possibility that residual or unmeasured confounding may persist. Third, time-related variables, including potential reverse causation (i.e., change in dietary intake due to diagnosed medical condition or disease), period of evaluation (i.e., baseline assessment or repeated over time), or duration of egg intake have been not investigated. Finally, the GRADE system may not be the best suit for assessing evidence in nutritional epidemiology, as by definition it tends to underestimate the strength of the evidence due to the observational nature of the studies. However, it helps to have a clearer idea of which can be the strengths and weaknesses of the studies evaluated (i.e., results from better quality studies are less heterogeneous and tend to show a decreased risk of CVD for moderate egg consumption) and a guide for future investigations.

\section{Conclusion}

Given the inconsistency of current findings on egg consumption and risk of CVD, future studies should improve the characterization of the population investigated, aiming to identify and remove genetic bias, such as the determinants of normal/hyper-response to dietary cholesterol. However, current evidence is not sufficient to address egg consumption 
as unhealthy nor to generalize potential detrimental effects to the whole population. While waiting for better designed and more complete studies overcoming the aforementioned limitations and lack of information on genetic profile, there may be no need to discourage egg consumption at the population level.

Author contributions Conceptualization: JG, GG; methodology: JG, GG; formal analysis and investigation: AM, GG; writing-original draft preparation: JG, GG; writing — review and editing: TB, ET, LI, AA, OHF, FG, MAMG, GG; supervision: MAMG, GG.

Funding This study was partially supported by a fund from the Italian Ministry of Health "Ricerca Corrente" (RC no. 2751594) (Dr. Godos). Open access funding provided by Università degli Studi di Catania within the CRUI-CARE Agreement.

\section{Compliance with ethical standards}

Conflict of interest The authors declare that they have no conflict of interest.

Ethical approval The manuscript does not contain clinical studies or patient data.

Open Access This article is licensed under a Creative Commons Attribution 4.0 International License, which permits use, sharing, adaptation, distribution and reproduction in any medium or format, as long as you give appropriate credit to the original author(s) and the source, provide a link to the Creative Commons licence, and indicate if changes were made. The images or other third party material in this article are included in the article's Creative Commons licence, unless indicated otherwise in a credit line to the material. If material is not included in the article's Creative Commons licence and your intended use is not permitted by statutory regulation or exceeds the permitted use, you will need to obtain permission directly from the copyright holder. To view a copy of this licence, visit http://creativecommons.org/licenses/by/4.0/.

\section{References}

1. Collaborators GBDCoD (2018) Global, regional, and national agesex-specific mortality for 282 causes of death in 195 countries and territories, 1980-2017: a systematic analysis for the Global Burden of Disease Study 2017. Lancet 392(10159):1736-1788. https://doi.org/10.1016/S0140-6736(18)32203-7

2. Collaborators GBDD (2019) Health effects of dietary risks in 195 countries, 1990-2017: a systematic analysis for the Global Burden of Disease Study 2017. Lancet 393(10184):1958-1972. https:// doi.org/10.1016/S0140-6736(19)30041-8

3. Collaborators GBDRF (2018) Global, regional, and national comparative risk assessment of 84 behavioural, environmental and occupational, and metabolic risks or clusters of risks for 195 countries and territories, 1990-2017: a systematic analysis for the Global Burden of Disease Study 2017. Lancet 392(10159):19231994. https://doi.org/10.1016/S0140-6736(18)32225-6

4. Lecerf JM, de Lorgeril M (2011) Dietary cholesterol: from physiology to cardiovascular risk. Br J Nutr 106(1):6-14. https://doi. org/10.1017/S0007114511000237
5. Clayton ZS, Fusco E, Kern M (2017) Egg consumption and heart health: a review. Nutrition 37:79-85. https://doi.org/10.1016/j. nut.2016.12.014

6. Berger S, Raman G, Vishwanathan R, Jacques PF, Johnson EJ (2015) Dietary cholesterol and cardiovascular disease: a systematic review and meta-analysis. Am J Clin Nutr 102(2):276-294. https://doi.org/10.3945/ajen.114.100305

7. Krauss RM, Eckel RH, Howard B, Appel LJ, Daniels SR, Deckelbaum RJ, Erdman JW Jr, Kris-Etherton P, Goldberg IJ, Kotchen TA, Lichtenstein AH, Mitch WE, Mullis R, Robinson K, WylieRosett J, St Jeor S, Suttie J, Tribble DL, Bazzarre TL (2000) AHA Dietary Guidelines: revision 2000: a statement for healthcare professionals from the Nutrition Committee of the American Heart Association. Circulation 102(18):2284-2299. https://doi. org/10.1161/01.cir.102.18.2284

8. Soliman GA (2018) Dietary cholesterol and the lack of evidence in cardiovascular disease. Nutrients. https://doi.org/10.3390/ nu10060780

9. Marventano S, Godos J, Tieri M, Ghelfi F, Titta L, Lafranconi A, Gambera A, Alonzo E, Sciacca S, Buscemi S, Ray S, Del Rio D, Galvano F, Grosso G (2020) Egg consumption and human health: an umbrella review of observational studies. Int J Food Sci Nutr 71(3):325-331. https://doi.org/10.1080/09637 486.2019.1648388

10. Schlesinger S, Neuenschwander M, Ballon A, Nothlings U, Barbaresko J (2020) Adherence to healthy lifestyles and incidence of diabetes and mortality among individuals with diabetes: a systematic review and meta-analysis of prospective studies. J Epidemiol Community Health 74(5):481-487. https://doi. org/10.1136/jech-2019-213415

11. Sterne JA, Hernan MA, Reeves BC, Savovic J, Berkman ND, Viswanathan M, Henry D, Altman DG, Ansari MT, Boutron I, Carpenter JR, Chan AW, Churchill R, Deeks JJ, Hrobjartsson A, Kirkham J, Juni P, Loke YK, Pigott TD, Ramsay CR, Regidor D, Rothstein HR, Sandhu L, Santaguida PL, Schunemann HJ, Shea B, Shrier I, Tugwell P, Turner L, Valentine JC, Waddington H, Waters E, Wells GA, Whiting PF, Higgins JP (2016) ROBINSI: a tool for assessing risk of bias in non-randomised studies of interventions. BMJ 355:i4919. https://doi.org/10.1136/bmj. i4919

12. Greenland S, Longnecker MP (1992) Methods for trend estimation from summarized dose-response data, with applications to meta-analysis. Am J Epidemiol 135(11):1301-1309

13. Orsini NBR, Greenland S (2006) Generalized least squares for trend estimation of summarized dose-response data. Stata J 6:40-57

14. Orsini N, Li R, Wolk A, Khudyakov P, Spiegelman D (2012) Meta-analysis for linear and nonlinear dose-response relations: examples, an evaluation of approximations, and software. Am J Epidemiol 175(1):66-73. https://doi.org/10.1093/aje/kwr265

15. Guyatt GH, Oxman AD, Vist GE, Kunz R, Falck-Ytter Y, Alonso-Coello P, Schunemann HJ, Group GW (2008) GRADE: an emerging consensus on rating quality of evidence and strength of recommendations. BMJ 336(7650):924-926. https ://doi.org/10.1136/bmj.39489.470347.AD

16. Hu FB, Stampfer MJ, Rimm EB, Manson JE, Ascherio A, Colditz GA, Rosner BA, Spiegelman D, Speizer FE, Sacks FM, Hennekens CH, Willett WC (1999) A prospective study of egg consumption and risk of cardiovascular disease in men and women. JAMA 281(15):1387-1394. https://doi.org/10.1001/ jama.281.15.1387

17. He K, Merchant A, Rimm EB, Rosner BA, Stampfer MJ, Willett WC, Ascherio A (2003) Dietary fat intake and risk of stroke in male US healthcare professionals: 14 year prospective cohort study. BMJ 327(7418):777-782. https://doi.org/10.1136/ bmj.327.7418.777 
18. Sauvaget C, Nagano J, Allen N, Grant EJ, Beral V (2003) Intake of animal products and stroke mortality in the Hiroshima/Nagasaki Life Span Study. Int J Epidemiol 32(4):536-543. https://doi. org/10.1093/ije/dyg151

19. Nakamura Y, Okamura T, Tamaki S, Kadowaki T, Hayakawa T, Kita Y, Okayama A, Ueshima H, Group NDR (2004) Egg consumption, serum cholesterol, and cause-specific and all-cause mortality: the National Integrated Project for Prospective Observation of Non-communicable Disease and Its Trends in the Aged, 1980 (NIPPON DATA80). Am J Clin Nutr 80(1):58-63. https:// doi.org/10.1093/ajen/80.1.58

20. Nakamura Y, Iso H, Kita Y, Ueshima H, Okada K, Konishi M, Inoue M, Tsugane S (2006) Egg consumption, serum total cholesterol concentrations and coronary heart disease incidence: Japan Public Health Center-based prospective study. Br J Nutr 96(5):921-928. https://doi.org/10.1017/bjn20061937

21. Qureshi AI, Suri FK, Ahmed S, Nasar A, Divani AA, Kirmani JF (2007) Regular egg consumption does not increase the risk of stroke and cardiovascular diseases. Med Sci Monit 13(1):CR1-8

22. Djousse L, Gaziano JM (2008) Egg consumption in relation to cardiovascular disease and mortality: the Physicians' Health Study. Am J Clin Nutr 87(4):964-969. https://doi.org/10.1093/ ajen/87.4.964

23. Djousse L, Gaziano JM (2008) Egg consumption and risk of heart failure in the Physicians' Health Study. Circulation 117(4):512-516. https://doi.org/10.1161/CIRCULATIO NAHA.107.734210

24. Nettleton JA, Steffen LM, Loehr LR, Rosamond WD, Folsom AR (2008) Incident heart failure is associated with lower whole-grain intake and greater high-fat dairy and egg intake in the Atherosclerosis Risk in Communities (ARIC) study. J Am Diet Assoc 108(11):1881-1887. https://doi.org/10.1016/j.jada.2008.08.015

25. Bernstein AM, Sun Q, Hu FB, Stampfer MJ, Manson JE, Willett WC (2010) Major dietary protein sources and risk of coronary heart disease in women. Circulation 122(9):876-883. https://doi. org/10.1161/CIRCULATIONAHA.109.915165

26. Scrafford CG, Tran NL, Barraj LM, Mink PJ (2011) Egg consumption and CHD and stroke mortality: a prospective study of US adults. Public Health Nutr 14(2):261-270. https://doi. org/10.1017/S1368980010001874

27. Zazpe I, Beunza JJ, Bes-Rastrollo M, Warnberg J, de la FuenteArrillaga C, Benito S, Vazquez Z, Martinez-Gonzalez MA, Investigators SUNP (2011) Egg consumption and risk of cardiovascular disease in the SUN Project. Eur J Clin Nutr 65(6):676-682. https ://doi.org/10.1038/ejen.2011.30

28. Bernstein AM, Pan A, Rexrode KM, Stampfer M, Hu FB, Mozaffarian D, Willett WC (2012) Dietary protein sources and the risk of stroke in men and women. Stroke 43(3):637-644. https://doi. org/10.1161/STROKEAHA.111.633404

29. Dilis V, Katsoulis M, Lagiou P, Trichopoulos D, Naska A, Trichopoulou A (2012) Mediterranean diet and CHD: the Greek European Prospective Investigation into Cancer and Nutrition cohort. Br J Nutr 108(4):699-709. https://doi.org/10.1017/S000711451 2001821

30. Misirli G, Benetou V, Lagiou P, Bamia C, Trichopoulos D, Trichopoulou A (2012) Relation of the traditional Mediterranean diet to cerebrovascular disease in a Mediterranean population. Am J Epidemiol 176(12):1185-1192. https://doi.org/10.1093/aje/kws20 5

31. Yaemsiri S, Sen S, Tinker L, Rosamond W, Wassertheil-Smoller S, He K (2012) Transfat, aspirin, and ischemic stroke in postmenopausal women. Ann Neurol 72(5):704-715. https://doi. org/10.1002/ana.23555

32. Goldberg S, Gardener H, Tiozzo E, Ying Kuen C, Elkind MS, Sacco RL, Rundek T (2014) Egg consumption and carotid atherosclerosis in the Northern Manhattan study. Atherosclerosis
235(2):273-280. https://doi.org/10.1016/j.atherosclerosis .2014 .04 .019

33. Haring B, Gronroos N, Nettleton JA, von Ballmoos MC, Selvin E, Alonso A (2014) Dietary protein intake and coronary heart disease in a large community based cohort: results from the Atherosclerosis Risk in Communities (ARIC) study [corrected]. PLoS ONE 9(10):e109552. https://doi.org/10.1371/journal.pone.01095 52

34. Haring B, Misialek JR, Rebholz CM, Petruski-Ivleva N, Gottesman RF, Mosley TH, Alonso A (2015) Association of dietary protein consumption with incident silent cerebral infarcts and stroke: the Atherosclerosis Risk in Communities (ARIC) Study. Stroke 46(12):3443-3450. https://doi.org/10.1161/STROK EAHA.115.010693

35. Larsson SC, Akesson A, Wolk A (2015) Egg consumption and risk of heart failure, myocardial infarction, and stroke: results from 2 prospective cohorts. Am J Clin Nutr 102(5):1007-1013. https:// doi.org/10.3945/ajen.115.119263

36. Virtanen JK, Mursu J, Virtanen HE, Fogelholm M, Salonen JT, Koskinen TT, Voutilainen S, Tuomainen TP (2016) Associations of egg and cholesterol intakes with carotid intima-media thickness and risk of incident coronary artery disease according to apolipoprotein E phenotype in men: the Kuopio Ischaemic Heart Disease Risk Factor Study. Am J Clin Nutr 103(3):895-901. https://doi. org/10.3945/ajcn.115.122317

37. Diez-Espino J, Basterra-Gortari FJ, Salas-Salvado J, Buil-Cosiales P, Corella D, Schroder H, Estruch R, Ros E, Gomez-Gracia E, Aros F, Fiol M, Lapetra J, Serra-Majem L, Pinto X, Babio N, Quiles L, Fito M, Marti A, Toledo E, Investigators P (2017) Egg consumption and cardiovascular disease according to diabetic status: the PREDIMED study. Clin Nutr 36(4):1015-1021. https:// doi.org/10.1016/j.clnu.2016.06.009

38. Farvid MS, Malekshah AF, Pourshams A, Poustchi H, Sepanlou SG, Sharafkhah M, Khoshnia M, Farvid M, Abnet CC, Kamangar F, Dawsey SM, Brennan P, Pharoah PD, Boffetta P, Willett WC, Malekzadeh R (2017) Dietary protein sources and all-cause and cause-specific mortality: the Golestan Cohort Study in Iran. Am J Prev Med 52(2):237-248. https://doi.org/10.1016/j.amepr e.2016.10.041

39. Guo J, Hobbs DA, Cockcroft JR, Elwood PC, Pickering JE, Lovegrove JA, Givens DI (2018) Association between egg consumption and cardiovascular disease events, diabetes and all-cause mortality. Eur J Nutr 57(8):2943-2952. https://doi.org/10.1007/ s00394-017-1566-0

40. Jang J, Shin MJ, Kim OY, Park K (2018) Longitudinal association between egg consumption and the risk of cardiovascular disease: interaction with type 2 diabetes mellitus. Nutr Diabetes 8(1):20. https://doi.org/10.1038/s41387-018-0033-1

41. Qin C, Lv J, Guo Y, Bian Z, Si J, Yang L, Chen Y, Zhou Y, Zhang H, Liu J, Chen J, Chen Z, Yu C, Li L, China Kadoorie Biobank Collaborative G (2018) Associations of egg consumption with cardiovascular disease in a cohort study of 0.5 million Chinese adults. Heart 104(21):1756-1763. https://doi.org/10.1136/heart jnl-2017-312651

42. Abdollahi AM, Virtanen HEK, Voutilainen S, Kurl S, Tuomainen TP, Salonen JT, Virtanen JK (2019) Egg consumption, cholesterol intake, and risk of incident stroke in men: the Kuopio Ischaemic Heart Disease Risk Factor Study. Am J Clin Nutr. https://doi. org/10.1093/ajen/nqz066

43. Xu L, Lam TH, Jiang CQ, Zhang WS, Zhu F, Jin YL, Woo J, Cheng KK, Thomas GN (2019) Egg consumption and the risk of cardiovascular disease and all-cause mortality: Guangzhou Biobank Cohort Study and meta-analyses. Eur J Nutr 58(2):785796. https://doi.org/10.1007/s00394-018-1692-3 
44. Zamora-Ros R, Cayssials V, Cleries R, Redondo ML, Sanchez MJ, Rodriguez-Barranco M, Sanchez-Cruz JJ, Mokoroa O, Gil L, Amiano P, Navarro C, Chirlaque MD, Huerta JM, Barricarte A, Ardanaz E, Moreno-Iribas C, Agudo A (2019) Moderate egg consumption and all-cause and specific-cause mortality in the Spanish European Prospective into Cancer and Nutrition (EPIC-Spain) study. Eur J Nutr 58(5):2003-2010. https://doi.org/10.1007/s0039 4-018-1754-6

45. Zhong VW, Van Horn L, Cornelis MC, Wilkins JT, Ning H, Carnethon MR, Greenland P, Mentz RJ, Tucker KL, Zhao L, Norwood AF, Lloyd-Jones DM, Allen NB (2019) Associations of dietary cholesterol or egg consumption with incident cardiovascular disease and mortality. JAMA 321(11):1081-1095. https://doi. org/10.1001/jama.2019.1572

46. Dehghan M, Mente A, Rangarajan S, Mohan V, Lear S, Swaminathan S, Wielgosz A, Seron P, Avezum A, Lopez-Jaramillo P, Turbide G, Chifamba J, AlHabib KF, Mohammadifard N, Szuba A, Khatib R, Altuntas Y, Liu X, Iqbal R, Rosengren A, Yusuf R, Smuts M, Yusufali A, Li N, Diaz R, Yusoff K, Kaur M, Soman B, Ismail N, Gupta R, Dans A, Sheridan P, Teo K, Anand SS, Yusuf S (2020) Association of egg intake with blood lipids, cardiovascular disease, and mortality in 177,000 people in 50 countries. Am J Clin Nutr 111(4):795-803. https://doi.org/10.1093/ajcn/nqz348

47. Djousse L, Ho YL, Nguyen XT, Quaden RM, Gagnon DR, Gaziano JM, Cho K (2019) Egg consumption and risk of coronary artery disease in the Million Veteran Program. Clin Nutr. https:// doi.org/10.1016/j.clnu.2019.12.017

48. Drouin-Chartier JP, Chen S, Li Y, Schwab AL, Stampfer MJ, Sacks FM, Rosner B, Willett WC, Hu FB, Bhupathiraju SN (2020) Egg consumption and risk of cardiovascular disease: three large prospective US cohort studies, systematic review, and updated meta-analysis. BMJ 368:m513. https://doi.org/10.1136/bmj.m513

49. Houston DK, Ding J, Lee JS, Garcia M, Kanaya AM, Tylavsky FA, Newman AB, Visser M, Kritchevsky SB, Health ABCS (2011) Dietary fat and cholesterol and risk of cardiovascular disease in older adults: the Health ABC Study. Nutr Metab Cardiovasc Dis 21(6):430-437. https://doi.org/10.1016/j.numecd.2009.11.007

50. Key TJ, Appleby PN, Bradbury KE, Sweeting M, Wood A, Johansson I, Kuhn T, Steur M, Weiderpass E, Wennberg M, Lund Wurtz AM, Agudo A, Andersson J, Arriola L, Boeing H, Boer JMA, Bonnet F, Boutron-Ruault MC, Cross AJ, Ericson U, Fagherazzi G, Ferrari P, Gunter M, Huerta JM, Katzke V, Khaw KT, Krogh V, La Vecchia C, Matullo G, Moreno-Iribas C, Naska A, Nilsson LM, Olsen A, Overvad K, Palli D, Panico S, MolinaPortillo E, Quiros JR, Skeie G, Sluijs I, Sonestedt E, Stepien M, Tjonneland A, Trichopoulou A, Tumino R, Tzoulaki I, van der Schouw YT, Verschuren WMM, di Angelantonio E, Langenberg C, Forouhi N, Wareham N, Butterworth A, Riboli E, Danesh J (2019) Consumption of Meat, Fish, Dairy Products, and Eggs and Risk of Ischemic Heart Disease. Circulation 139(25):2835-2845. https://doi.org/10.1161/CIRCULATIONAHA.118.038813

51. Tong TYN, Appleby PN, Key TJ, Dahm CC, Overvad K, Olsen A, Tjonneland A, Katzke V, Kuhn T, Boeing H, Karakatsani A, Peppa E, Trichopoulou A, Weiderpass E, Masala G, Grioni S, Panico S, Tumino R, Boer JMA, Verschuren WMM, Quiros JR, Agudo A, Rodriguez-Barranco M, Imaz L, Chirlaque MD, Moreno-Iribas C, Engstrom G, Sonestedt E, Lind M, Otten J, Khaw KT, Aune D, Riboli E, Wareham NJ, Imamura F, Forouhi NG, di Angelantonio E, Wood AM, Butterworth AS, Perez-Cornago A (2020) The associations of major foods and fibre with risks of ischaemic and haemorrhagic stroke: a prospective study of 418329 participants in the EPIC cohort across nine European countries. Eur Heart J 41(28):2632-2640. https://doi.org/10.1093/eurheartj/ehaa007

52. Trichopoulou A, Psaltopoulou T, Orfanos P, Trichopoulos D (2006) Diet and physical activity in relation to overall mortality amongst adult diabetics in a general population cohort. J Intern Med 259(6):583-591. https://doi.org/10.111 $1 / \mathrm{j} .1365-2796.2006 .01638 . x$

53. van den Brandt PA (2019) Red meat, processed meat, and other dietary protein sources and risk of overall and cause-specific mortality in The Netherlands Cohort Study. Eur J Epidemiol 34(4):351-369. https://doi.org/10.1007/s10654-019-00483-9

54. Xia X, Liu F, Yang X, Li J, Chen J, Liu X, Cao J, Shen C, Yu L, Zhao Y, Wu X, Zhao L, Li Y, Huang J, Lu X, Gu D (2020) Associations of egg consumption with incident cardiovascular disease and all-cause mortality. Sci China Life Sci 63(9):1-11. https://doi. org/10.1007/s11427-020-1656-8

55. Deng C, Lu Q, Gong B, Li L, Chang L, Fu L, Zhao Y (2018) Stroke and food groups: an overview of systematic reviews and meta-analyses. Public Health Nutr 21(4):766-776. https://doi. org/10.1017/S1368980017003093

56. Alexander DD, Miller PE, Vargas AJ, Weed DL, Cohen SS (2016) Meta-analysis of egg consumption and risk of coronary heart disease and stroke. J Am Coll Nutr 35(8):704-716. https://doi. org/10.1080/07315724.2016.1152928

57. Mazidi M, Katsiki N, Mikhailidis DP, Pencina MJ, Banach M (2019) Egg consumption and risk of total and cause-specific mortality: an individual-based cohort study and pooling prospective studies on behalf of the Lipid and Blood Pressure Meta-analysis Collaboration (LBPMC) group. J Am Coll Nutr 38(6):552-563. https://doi.org/10.1080/07315724.2018.1534620

58. Takagi H, Hari Y, Nakashima K, Kuno T, Ando T, Group A (2020) Egg consumption and coronary artery disease: a nice knockdown argument. Angiology. https://doi.org/10.1177/000331971989749 3

59. Shin JY, Xun P, Nakamura Y, He K (2013) Egg consumption in relation to risk of cardiovascular disease and diabetes: a systematic review and meta-analysis. Am J Clin Nutr 98(1):146-159. https://doi.org/10.3945/ajcn.112.051318

60. Bechthold A, Boeing H, Schwedhelm C, Hoffmann G, Knuppel S, Iqbal K, De Henauw S, Michels N, Devleesschauwer B, Schlesinger S, Schwingshackl L (2019) Food groups and risk of coronary heart disease, stroke and heart failure: a systematic review and dose-response meta-analysis of prospective studies. Crit Rev Food Sci Nutr 59(7):1071-1090. https://doi.org/10.1080/10408 398.2017.1392288

61. Khawaja O, Singh H, Luni F, Kabour A, Ali SS, Taleb M, Ahmed $\mathrm{H}$, Gaziano JM, Djousse L (2017) Egg consumption and incidence of heart failure: a meta-analysis of prospective cohort studies. Front Nutr 4:10. https://doi.org/10.3389/fnut.2017.00010

62. Astrup A, Bertram HC, Bonjour JP, de Groot LC, de Oliveira Otto MC, Feeney EL, Garg ML, Givens I, Kok FJ, Krauss RM, Lamarche B, Lecerf JM, Legrand P, McKinley M, Micha R, Michalski MC, Mozaffarian D, Soedamah-Muthu SS (2019) WHO draft guidelines on dietary saturated and trans fatty acids: time for a new approach? BMJ 366:14137. https://doi.org/10.1136/ bmj.14137

63. Richard C, Cristall L, Fleming E, Lewis ED, Ricupero M, Jacobs RL, Field CJ (2017) Impact of egg consumption on cardiovascular risk factors in individuals with type 2 diabetes and at risk for developing diabetes: a systematic review of randomized nutritional intervention studies. Can J Diabetes 41(4):453-463. https ://doi.org/10.1016/j.jcjd.2016.12.002

64. Rouhani MH, Rashidi-Pourfard N, Salehi-Abargouei A, Karimi M, Haghighatdoost F (2018) Effects of egg consumption on blood lipids: a systematic review and meta-analysis of randomized clinical trials. J Am Coll Nutr 37(2):99-110. https://doi. org/10.1080/07315724.2017.1366878

65. Miranda JM, Anton X, Redondo-Valbuena C, Roca-Saavedra P, Rodriguez JA, Lamas A, Franco CM, Cepeda A (2015) Egg and egg-derived foods: effects on human health and use as functional foods. Nutrients 7(1):706-729. https://doi.org/10.3390/nu7010706 
66. Mine Y (2007) Egg proteins and peptides in human health-chemistry, bioactivity and production. Curr Pharm Des 13(9):875-884

67. Shinn SE, Proctor A, Baum JI (2018) Egg yolk as means for providing essential and beneficial fatty acids. J Am Oil Chem Soc 95:5-11. https://doi.org/10.1002/aocs.12008

68. Zeisel SH, da Costa KA (2009) Choline: an essential nutrient for public health. Nutr Rev 67(11):615-623. https://doi.org/10.111 $1 / \mathrm{j} .1753-4887.2009 .00246 . \mathrm{x}$

69. Tang WH, Wang Z, Levison BS, Koeth RA, Britt EB, Fu X, Wu Y, Hazen SL (2013) Intestinal microbial metabolism of phosphatidylcholine and cardiovascular risk. N Engl J Med 368(17):15751584. https://doi.org/10.1056/NEJMoa1 109400

70. Miller CA, Corbin KD, da Costa KA, Zhang S, Zhao X, Galanko JA, Blevins T, Bennett BJ, O'Connor A, Zeisel SH (2014) Effect of egg ingestion on trimethylamine- $\mathrm{N}$-oxide production in humans: a randomized, controlled, dose-response study. Am J Clin Nutr 100(3):778-786. https://doi.org/10.3945/ajcn.114.087692

71. Blesso CN (2015) Egg phospholipids and cardiovascular health. Nutrients 7(4):2731-2747. https://doi.org/10.3390/nu7042731

72. Giordano E, Quadro L (2018) Lutein, zeaxanthin and mammalian development: Metabolism, functions and implications for health. Arch Biochem Biophys 647:33-40. https://doi.org/10.1016/j. abb.2018.04.008

73. Fernandez ML (2010) Effects of eggs on plasma lipoproteins in healthy populations. Food Funct 1(2):156-160. https://doi. org/10.1039/c0fo00088d

74. Johnson LA, Arbones-Mainar JM, Fox RG, Pendse AA, Altenburg MK, Kim HS, Maeda N (2011) Apolipoprotein E4 exaggerates diabetic dyslipidemia and atherosclerosis in mice lacking the LDL receptor. Diabetes 60(9):2285-2294. https://doi.org/10.2337/ db11-0466
75. Sacks FM (2015) The crucial roles of apolipoproteins E and C-III in apoB lipoprotein metabolism in normolipidemia and hypertriglyceridemia. Curr Opin Lipidol 26(1):56-63. https://doi. org/10.1097/MOL.0000000000000146

76. Yu XH, Qian K, Jiang N, Zheng XL, Cayabyab FS, Tang CK (2014) ABCG5/ABCG8 in cholesterol excretion and atherosclerosis. Clin Chim Acta 428:82-88. https://doi.org/10.1016/j. cca.2013.11.010

77. Francis GS (2017) Cholesterol and heart failure: is there an important connection? J Am Coll Cardiol 70(17):2137-2138. https:// doi.org/10.1016/j.jacc.2017.08.068

78. Okuyama H, Langsjoen PH, Hamazaki T, Ogushi Y, Hama R, Kobayashi T, Uchino H (2015) Statins stimulate atherosclerosis and heart failure: pharmacological mechanisms. Expert Rev Clin Pharmacol 8(2):189-199. https://doi.org/10.1586/17512 433.2015.1011125

79. Bennion LJ, Grundy SM (1977) Effects of diabetes mellitus on cholesterol metabolism in man. N Engl J Med 296(24):13651371. https://doi.org/10.1056/NEJM197706162962401

80. Ooi EM, Ng TW, Chan DC, Watts GF (2009) Plasma markers of cholesterol homeostasis in metabolic syndrome subjects with or without type-2 diabetes. Diabetes Res Clin Pract 85(3):310-316. https://doi.org/10.1016/j.diabres.2009.06.003

81. Liu S, Liu J, Weng R, Gu X, Zhong Z (2019) Apolipoprotein E gene polymorphism and the risk of cardiovascular disease and type 2 diabetes. BMC Cardiovasc Disord 19(1):213. https://doi. org/10.1186/s12872-019-1194-0

\section{Affiliations}

\section{Justyna Godos ${ }^{1}$ - Agnieszka Micek ${ }^{2}$. Tomasz Brzostek ${ }^{3}$ - Estefania Toledo ${ }^{4,5,6} \cdot$ Licia lacoviello $^{7,8}$ - Arne Astrup ${ }^{9}$. Oscar H. Franco ${ }^{10,11} \cdot$ Fabio Galvano $^{12}$ - Miguel A. Martinez-Gonzalez $z^{4,5,6,13} \cdot$ Giuseppe Grosso $^{12}$ (1)}

1 Oasi Research Institute, IRCCS, Troina, Italy

2 Department of Nursing Management and Epidemiology Nursing, Faculty of Health Sciences, Jagiellonian University Medical College, Kraków, Poland

3 Department of Internal Medicine and Community Nursing, Faculty of Health Sciences, Jagiellonian University Medical College, Kraków, Poland

4 Department of Preventive Medicine and Public Health, School of Medicine, University of Navarra, Pamplona, Navarre, Spain

5 CIBER Physiopathology of Obesity and Nutrition (CIBEROBN), Carlos III Institute of Health, Madrid, Spain

6 Navarra Institute for Health Research, IdiSNA, Pamplona, Navarre, Spain

7 Department of Epidemiology and Prevention, IRCCS NEUROMED, Pozzilli, IS, Italy
8 Department of Medicine and Surgery, Research Centre in Epidemiology and Preventive Medicine (EPIMED), University of Insubria, Varese, Italy

9 Department of Nutrition, Exercise, and Sports, Faculty of Science, University of Copenhagen, Nørre Campus, Copenhagen, Denmark

10 Department of Epidemiology, Erasmus MC, University Medical Center Rotterdam, Rotterdam, Netherlands

11 Institute of Social and Preventive Medicine, University of Bern, Bern, Switzerland

12 Department of Biomedical and Biotechnological Sciences, University of Catania, Via S. Sofia 97, 95123 Catania, Italy

13 Department of Nutrition, Harvard T.H. Chan School of Public Health, Boston, MA, USA 